\title{
Travelling Fires for Structural Design Part II: Design Methodology
}

\author{
Jamie Stern-Gottfried ${ }^{1,2}$ and Guillermo Rein ${ }^{1}, *$ \\ 1: School of Engineering, University of Edinburgh, EH9 3JL, UK \\ 2: $\quad$ Arup, London, W1T 4BQ, UK \\ ${ }^{*}$ Corresponding author at: \\ Imperial College London, UK, SW72AZ \\ E-mail address: g.rein@imperial.ac.uk
}

\section{Abstract}

Close inspection of accidental fires in large, open-plan compartments reveals that they do not burn simultaneously throughout the whole enclosure. Instead, these fires tend to move across floor plates as flames spread, burning over a limited area at any one time. These fires have been labelled "travelling fires". Current structural fire design methods do not account for these types of fires. Despite these observations, fire scenarios most commonly used for the structural design of modern buildings are based on traditional methods that assume uniform burning and homogenous temperature conditions throughout a compartment, regardless of its size.

This paper is Part II of a two part article and gives details of a design methodology using travelling fires to produce more realistic fire scenarios in large, open-plan compartments than the conventional methods that assume uniform burning. The methodology considers a range of possible fire sizes and is aimed at producing results consistent with the requirements of structural fire analysis. The methodology is applied to a case study of a generic concrete frame by means of heat transfer calculations to infer structural performance. It is found that fire that is $10 \%$ of the floor area is the most onerous for the structure, producing rebar temperatures equivalent to exposure of 106min of the standard fire and approximately $200^{\circ} \mathrm{C}$ hotter than that calculated by using the Eurocode 1 parametric temperature-time curve. A detailed sensitivity is presented, concluding that the results of 
the method are independent of the grid size selected and the most sensitive input parameters are related to the building design and its use and not the physical assumptions or numerical implementation of the model.

Keywords: travelling fires, structures and fire, design fires, building fire safety

\subsection{Introduction}

Close inspection of accidental fires in large, open-plan compartments reveals that they do not burn simultaneously throughout an entire compartment. Instead, these fires tend to move across floor plates as flames spread, burning over a limited area at any one time. These fires have been labelled "travelling fires".

Despite these observations, fire scenarios currently used for the structural fire design of modern buildings are based on one of two traditional methods for specifying the thermal environment; the standard temperature-time curve (which has its origins in the late $19^{\text {th }}$ century [1]) or parametric temperature-time curves, such as that specified in Eurocode 1 [2]. These methods assume uniform burning and homogenous temperature conditions throughout a compartment, regardless of its size. These two assumptions, which have never been confirmed experimentally, led to limitations in the use of the traditional methods in large compartments. Details of the limitations and their implications are given in Part I of this paper and in the literature $[3,4,5]$.

Accidental fires that have led to structural failure $[6,7,8,9]$ have been observed to travel across floor plates, and vertically between floors, rather than burn uniformly. Travelling fires have also been observed experimentally in compartments with non-uniform ventilation $[10,11,12]$.

Even though the traditional methods have inherent assumptions of fire behaviour different from that observed in accidental and experimental fires, in the past they were generally deemed to be conservative, and therefore appropriate for engineering design. However, 
recently travelling fires have been shown to be more challenging to structures than the design fires from traditional methods $[4,13]$. Moreover, recent advances in structural analysis and modelling techniques are aimed at determining the true performance of a building exposed to fire. Therefore, there is a need for a more realistic definition of fire scenarios to obtain a more accurate characterisation of building performance. Because current engineering analysis of the structural response often involves the use of sophisticated computer modelling, it is also important to ensure a consistent level of crudeness across the whole analysis $[14,15]$.

To address this need, a methodology that utilises physically-based fire dynamics for large enclosures, based on travelling fires, has been developed. It has been formulated to enable collaboration between fire safety engineers to define the fire environment and structural fire engineers to assess the subsequent structural behaviour, which is an identified need within the structural fire community $[14,15]$.

This paper presents the general framework and analytical details of this travelling fires methodology, which produces temperature fields for a range of fire sizes. These results are used to calculate the heating of a generic concrete structure. A sensitivity study is conducted to determine the relative impact of the methodology's numerical, physical and building parameters on the structure.

\subsection{Travelling Fires Framework}

The goal of the methodology developed in this paper is to calculate the fire-induced thermal field such that it is physically-based, compatible with the subsequent structural analysis, and accounts for the fire dynamics relevant to the specific building being studied. In order to achieve this, a fire model must be selected that provides the spatial and temporal evolution of the temperature field. This model is then applied to the particular compartment of interest. 
The fire-induced thermal field is divided in two regions: the near field and the far field. These regions are relative to the fire, which travels within the compartment, and therefore move with it. The near field is the burning region of the fire and where structural elements are exposed directly to flames and experience the most intense heating. The far field is the region remote from the flames where structural elements are exposed to hot combustion gases (the smoke layer) but experience less intense heating than from the flames. The near and far fields are illustrated in Figure 2.1.

Because the initiation and end of the fire results in a very fast rise and decrease of the gas temperature relative to the structural heating, these phases can be assumed as instantaneous for the temperature field (see figures in Section 2.5.2 for a fast return to ambient). This is because the larger an enclosure is, the lower the importance of the thermal inertial of its linings are, thus the faster the growth and decay phases will be. In other words, the transport of the hot gases in the smoke layer is faster than the heat transfer to the surfaces. Note that the cooling of the structure is not neglected; only the brief decay phase of the fire environment is shortened.

For most large compartments, travelling fires are likely to be fuel bed controlled. In fact, a recent review by Majdalani and Torero [16] of early CIB tests and the resulting analyses of compartment fire behaviour done by Philip Thomas and others highlights that ventilation controlled fires are unlikely in large enclosures and that they are not necessarily more conservative for structural analysis than fuel bed controlled fires. Majdalani and Torero note that while the different burning behaviour between ventilation and fuel bed controlled fires was clearly stated in the original studies, ventilation controlled fires have nonetheless been assumed to be the most severe case for design. Therefore traditional methods of calculating the burning rate, based on correlations for ventilation limited fires in relatively small compartments, are inappropriate for use with travelling fires.

The methodology does not assume a single, fixed fire scenario but rather accounts for a whole family of possible fires, ranging from small fires travelling across the floor plate for long durations with mostly low temperatures to large fires burning for short durations with 
high temperatures. Temperature-time curves for a family of fires are shown in Figure 2.2. Using the family of fires enables the methodology to overcome the fact that the exact size of an accidental fire cannot be determined a priori. This range of fires allows identification of the most challenging heating scenarios for the structure to be used as input to the subsequent structural analysis.

Each fire in the family burns over a specific surface area, denoted as $A_{f}$, which is a percentage of the total floor area, $A$, of the building, ranging from $1 \%$ to $100 \%$. Compared to this approach, the conventional methods only consider full size fires, which are analogous to the $100 \%$ fire size in this methodology. All other burning areas represent travelling fires of different sizes which are not considered in the conventional methods.

The methodology is independent of the fire model selected and can utilise simple analytical expressions or sophisticated numerical simulations. The first application of this methodology was done using the Computational Fluid Dynamics (CFD) code Fire Dynamics Simulator (FDS) as the fire model [17]. Later work was developed using an analytical correlation $[4,13,18]$. The work in this paper is developed further from the earlier analytical work of [4]. Details of each step of the methodology are given in the following section.

\subsection{Analytical Model}

The analytical correlation used, in lieu of CFD modelling, was selected for the several reasons. The analytical model is simple and easy to use, while still providing the correct dynamics (see Section 2.3.2). It also provides a consistent level of crudeness with the heat transfer calculations performed to assess structural performance. And it does not have the high computational cost of CFD (which is on the order of days to calculate one fire scenario) associated with it and, therefore, enables consideration of many more scenarios and sensitivity studies than would have been practical with CFD models.

It is noted, however, that the correlation used is a simplification of the actual fire dynamics of the cases being examined and is only applicable to a limited set of scenarios where it is 
valid, such as a single floor without interconnection to other levels. However, given the benefits of the points listed above, the analytical correlation was deemed sufficient to progress development of the methodology.

The following sections present the details needed to calculate the temperature field for the family of fires, using the analytical correlation selected.

\subsubsection{Burning Times}

As the exact size of a potential fire in a building cannot be determined a priori, and the calculation methods for burning rates are inappropriate for large compartments, this methodology must assume the heat release rate of a fire and investigate a wide range of possible sizes. It is assumed that there is a uniform fuel load across the fire path and that the fire will burn at a constant heat release per unit area typical of the building load under study. From this, the total heat release rate is calculated by Eq. (2.1).

$$
\dot{Q}=A_{f} \dot{Q}^{\prime \prime}
$$

where $\dot{Q}$ is the total heat release of the fire $(\mathrm{kW})$

$A_{f}$ is the floor area of the fire $\left(\mathrm{m}^{2}\right)$

$\dot{Q}^{\prime \prime}$ is the heat release rate per unit area $\left(\mathrm{MW} / \mathrm{m}^{2}\right)$

The local burning time of the fire over area, $A_{f}$, is calculated by Eq. (2.2).

$$
t_{b}=\frac{q_{f}}{\dot{Q}^{\prime \prime}}
$$

where $t_{b}$ is the burning time (s)

$q_{f}$ is the fuel load density $\left(\mathrm{MJ} / \mathrm{m}^{2}\right)$

For the case study presented below, the fuel load density, $q_{f}$, is assumed to be $570 \mathrm{MJ} / \mathrm{m}^{2}$, as per the $80^{\text {th }}$ percentile design value [19] for office buildings. The heat release rate per unit area, $\dot{Q}^{\prime \prime}$, is taken as $500 \mathrm{~kW} / \mathrm{m}^{2}$ which is deemed to be a typical value for densely furnished 
spaces, as design guidance [20] gives this value for retail spaces. Based on these two values, the characteristic burning time, $t_{b}$, is calculated by Eq. (2.2) to be $19 \mathrm{~min}$. This time correlates well to the free-burning fire duration of domestic furniture, which Walton and Thomas [21] note is about 20min. It is also in line with Harmathy's [22] observation that a fully developed, well ventilated fire will normally last less than 30min.

Note that the burning time is independent of the burning area. Thus the $100 \%$ burning area and the $1 \%$ burning area will both consume all of the fuel over the specified area in the same time, $t_{b}$. However, a travelling fire moves from one burning area to the next so that the total burning duration, $t_{\text {total }}$, across the floor plate is extended (see Eq. (2.9) in Section 2.3.3). This means that there is a longer total burning duration for smaller burning areas.

The total burning duration for a single fire size can reach a theoretical maximum, denoted as $t_{\text {total }}^{*}$, which is equal to the local burning time multiplied by the ratio of floor area to the fire size, plus one an additional local burning time. For example, a $25 \%$ fire has a ratio of floor area to fire area of four, so adding one local burning time to this gives five times the local burning time, or 95min, for the total burning duration. Similarly, the maximum total burning duration for a $1 \%$ fire is $1919 \mathrm{~min}$. For full details of the derivation of $t_{\text {total }}^{*}$, see Eq. (2.10) in Section 2.3.3.

\subsubsection{Near Field vs. Far Field}

The near field is dominated by the presence of flames. The maximum possible structural heating would result from direct contact of the flames and a structural element. Hence it is assumed that there is direct contact and peak flame temperatures are used in this methodology. These temperatures have been measure in small fires in the range of 800 to $1000^{\circ} \mathrm{C}$ [23] and up to $1200^{\circ} \mathrm{C}$ in larger fires [24]. The maximum value of $1200^{\circ} \mathrm{C}$ is chosen here for the near field temperature to represent worst case conditions. A sensitivity study on the effect of this parameter value over the whole experimental range of peak flame temperatures is presented in Section 2.5.7. 
The far field temperature decreases with the distance from the fire. The maximum exposure to hot gases results when the structural element is on the exposed side of the ceiling. Therefore temperatures at the ceiling are used in this methodology. An analytical expression capturing the decrease of temperature with distance as a function of the fire heat release rate would take the general form given in Eq. (2.3).

$$
T_{f f}(x)=c \dot{Q}_{c}^{\alpha} x^{-\beta}
$$

where $T_{f f}$ is the far field temperature $\left({ }^{\circ} \mathrm{C}\right)$

$\dot{Q}_{c}$ is the convective heat release rate $(\mathrm{W})$

c is a constant parameter related to geometry and physical properties (-)

$x$ is the horizontal distance from the fire $(\mathrm{m})$

$\alpha$ is the power law coefficient for heat release rate (-)

$\beta \quad$ is the power law coefficient for distance (-)

The decrease with distance is due to the incremental mixing of hot gases with fresh air as they flow away from the fire source. This is a similar mixing process that takes places in a vertical turbulent fire plume. The scale analysis of an inert mixing plume [24, 25] gives $\alpha$ of $2 / 3$ and $\beta$ of $5 / 3$.

The experimental and theoretical work by Alpert [26] provides the full expression and the coefficients valid for an axi-symmetric, unconfined ceiling jet as a function of radial distance from the fire centre. The correlation is given below in Eq. (2.4). Alpert found experimentally that $\alpha$ and $\beta$ are both $2 / 3$, and that there is a dependence on the inverse of the ceiling height (thus yielding a combined power law coefficient for the spatial distance of $5 / 3$ as predicted by the scale analysis).

$$
T_{\max }-T_{\infty}=\frac{5.38(\dot{Q} / r)^{2 / 3}}{H}
$$

where $T_{\max }$ is the maximum ceiling jet temperature $\left({ }^{\circ} \mathrm{C}\right)$

$T_{\infty} \quad$ is the ambient temperature $\left({ }^{\circ} \mathrm{C}\right)$ 


$$
\begin{aligned}
& \dot{Q} \quad \text { is the total heat release rate }(\mathrm{kW}) \\
& r \quad \text { is the distance from the centre of the fire }(\mathrm{m}) \\
& H \quad \text { is the floor to ceiling height }(\mathrm{m})
\end{aligned}
$$

The Alpert correlation uses the total heat release rate, rather than its convective portion which is related to buoyancy. This was due to the fact that the heat release rates of pool fires, which were the basis of the correlation, are often reported as total values and not convective [27]. The specific pool fires used for the development of the Alpert correlations were alcohol pool fires, in which the radiative fraction is negligible. Therefore, for application in this methodology, the heat release rate is assumed to be purely convective, i.e. the radiative fraction is taken to be zero.

Alpert gives a piecewise equation for maximum ceiling jet temperatures to describe the near field $(\mathrm{r} / \mathrm{H} \leq 0.18)$ and far field $(\mathrm{r} / \mathrm{H}>0.18)$ temperatures. But only the far field equation is used here. The methodology assumes the near field to be the flame and does not use the temperature expression given by Alpert. If the results of Eq. (2.4) exceed the specified near field temperature at any point, they are capped at flame temperature.

This correlation was used in previous work of this methodology $[4,13,18]$. Its use for horizontally travelling fires requires the further assumption that the coefficient, $c$, does not change significantly when the linear distance, $x$, replaces the radial distance, $r$, given by Alpert (planar vs. axi-symmetrical configurations). Therefore, the linear distance, $x$, is used in the methodology.

It is also noted that the correlation assumes an unconfined ceiling with no accumulated smoke layer. However, these strict limitations are ignored in the application to this methodology. This has been done as it is a simple correlation and was chosen to provide an approximate and straightforward calculation of the temperature field that is sufficient to progress the development of the methodology. Further sophistication and accuracy could be added to this framework as needed. 
As a point of comparison between the axi-symmetric ceiling jet correlation and a planar case, a set of CFD simulations were run using FDS v5.5.3. The simulations examined the temperature decrease with linear distance from a 147MW fire (the $25 \%$ fire size examined in Section 2.5) over a $28 \mathrm{~m}$ wide strip located at one end of a large compartment $42 \mathrm{~m}$ long by $28 \mathrm{~m}$ wide and $3.6 \mathrm{~m}$ high (see Section 2.4 for details). A grid sensitivity study was conducted to ensure good resolution and the final cell size was set at $40 \mathrm{~cm}$. Three cases were investigated: $100 \%$ ventilation opening (the whole façade is open), $50 \%$ ventilation opening, and $25 \%$ ventilation opening. While very different ventilation scenarios were investigated, Figure 2.3 shows that the ceiling jet correlation provides a similar decay with distance (similar $\beta$ value) to the FDS models. The temperature agreement is better at larger distances.

The values of $\beta$ for the three FDS curves are 0.605 for $100 \%$ ventilation, 0.502 for $50 \%$ ventilation, and 0.463 for $25 \%$ ventilation. These values are similar to the $2 / 3 \beta$ value from Alpert's correlation. The modelling results provide confidence that the ceiling jet correlation, while not exactly capturing the fire dynamics of each scenario of interest here, gives appropriate and conservative results.

The previous work of this methodology $[4,13,17,18]$ took a single representative temperature for the far field for each fire size, independent of distance. The work in this paper, however, relaxes this simplification and allows for spatially varying far field temperatures to be carried into the heating calculations. While this creates more information to pass to the structural analysis, it provides a more accurate representation of the fire dynamics for each scenario, which may be particularly important for analyses of whole frame behaviour.

\subsubsection{Spatial Discretisation}

It is assumed that the fire extends the whole width of the building and travels in a linear path along the structure's length. Other fire paths are possible but results shown in [4] demonstrate that they do not greatly alter the structural response. Thus a single linear path is chosen for this further development of the methodology. As the far field temperature is assumed uniform along the width of the building but varies along its length for the assumed 
linear path, the problem is treated as one-dimensional. Thus the far field temperature for any given fire size can be calculated at any position in the structure by its linear distance from the fire. This discretisation is similar to the strips examined by Clifton in his Large Firecell Model [28].

The fire is assumed to travel at a constant spread rate, $s$, across the floor plate. This is calculated by Eq. (2.5) and is related to the burning time and the fire size.

$$
s=\frac{L_{f}}{t_{b}}
$$

where $s$ is the spread rate $(\mathrm{m} / \mathrm{s})$

$L_{f}$ is the length of the fire $(\mathrm{m})$

Given that there is a fixed local burning time (based on the assumption of a uniform fuel load density and a constant heat release rate per unit area, as explained in Section 2.3.1), there is a one-to-one relationship between fire size and spread rate. This corresponds with the logic that the bigger the fire, the faster it moves. For example, a fire that is $50 \%$ of the floor area $\left(L_{f}=0.5 L\right)$ would have a spread rate five times faster than a $10 \%$ fire $\left(L_{f}=0.1 L\right)$, as the local burning time is the same for both.

To track the fire location over time and enable calculation of the far field temperature at various distances, the building is broken up into numerous nodes, each with a fixed width $\Delta x$ (also referred to as the grid size). Each node has a single far field temperature at any given time. Therefore the more elements that are used, the better resolved the far field temperature is (see Section 2.5.2). As the fire travels across the floor plate, nodes go from being unburnt, to on fire, to burnt out.

Figure 2.4 illustrates the one-dimensional discretisation of the building showing the grid size $(\Delta x)$, total length $(L)$, fire length $\left(L_{f}\right)$, far field distance $\left(x_{f f}\right)$, node references, and the leading and trailing edges of the fire. The near field distance is half the fire length, while the far field distance $\left(x_{f f}\right)$ is taken from the fire centre to the node being examined (node $i$ ). 
Each node can be described by its index, varying from 1 to $n$. The distance, $x_{i}$, from a fixed reference point, taken here as the left end of the structure where the fire is assumed to start, to another point can be described by Eq. (2.6).

$$
x_{i}=(i-0.5) \Delta x
$$

where $x_{i}$ is the position relative to the end of the structure (m)

$i$ is the node reference (-)

$\Delta x$ is the grid size (m), also given by $L / n$

The relative positions of the fire location and the node can be tracked over time to give a full transient evolution of the temperature field, including the passage of the near and far fields (see Figure 2.1b and Figure 2.2). In order to adequately resolve the movement of the fire, the time step, $\Delta t^{*}$, is determined by Eq. (2.7).

$$
\Delta t^{*}=\frac{\Delta x}{S}
$$

This definition allows the time step to capture the movement of the fire from one node to the next. If the time step is longer than that calculated by Eq. (2.7), then important information is lost. However, note that there is no benefit in making a smaller time step. This is because a node cannot be partially occupied by the fire, and thus each node has only one temperature for each time step. A finer time step would yield consecutive times with the same temperature. Therefore the time step in this work is always set by Eq. (2.7).

The time the fire spends at one node location, $t_{i}$, is the sum of the travel time across the node plus one local burning time. The whole node is assumed to start burning when the leading edge of the fire enters from the near side. Then the whole node is burnt out when the trailing edge of the fire passes the far side. This is given by Eq. (2.8).

$$
t_{i}=\frac{\Delta x}{s}+t_{b}
$$


As the fire travels across $n-1$ nodes (the initial condition has node 1 burning at $t=0$ ), the total burning duration, $t_{\text {total }}$, is the travel time across the rest of the floor plate plus one burning time. This fact, plus noting that $n=L / \Delta x$, means the total burning duration is given by Eq. (2.9).

$$
t_{\text {total }}=t_{b}\left(\frac{L-\Delta x}{L_{f}}+1\right)
$$

As can be seen from Eq. (2.9), the total burning duration is a multiple of the local burning time. This multiple of the local burning time is greater for smaller fire sizes, meaning longer total burning durations. This explains why travelling fires account for the longest burning fires that can take place in a large compartment and, indeed, those observed in accidental fires [3].

Note that the total burning time also depends on the grid size (due to the initial condition). The largest grid size that can be used to ensure that a given fire size is fully resolved is $\Delta x=L_{f}$. A larger grid size would lead to the fire only occupying a portion of any node, which is inconsistent with the assumptions of this methodology. Placing this maximum grid size in Eq. (2.9), gives a total burning time of $t_{\text {total }}=t_{b}\left(L / L_{f}\right)$. For example, the total burning duration for a $25 \%$ fire is $76 \mathrm{~min}$, which is four times the local burning time (19min). The approach taken in earlier work $[4,13,18]$ used the largest grid size only and therefore had total burning durations along these lines. However, as the grid size is reduced, the total burning duration increases. The longest possible total burning duration, denoted as $t_{\text {total }}^{*}$, is the limit of $t_{\text {total }}$ as the grid size approaches zero (the smallest possible grid size), as given in Eq. (2.10).

$$
t_{\text {total }}^{*}=\lim _{\Delta x \rightarrow 0} t_{\text {total }}=t_{b}\left(\frac{L}{L_{f}}+1\right)
$$

This means that the total burning duration is up to one local burning time longer with a fine grid resolution than with a coarse one. For the same $25 \%$ fire size example, the total burning 
duration with a very well resolved grid would approach five times the local burning time, or 95min. This additional burning time, which was not considered in previous versions of the methodology, represents the time period of initial fire growth before the fire reaches its full size and the final stages of the fire as burns out and is again smaller than its full size. This is not accounted for in the coarse grid case, which assumes the fire initialises and burns out at its peak size.

\subsection{Application to a Generic Structure}

The travelling fires methodology presented here is applied here to a case study of a generic concrete frame, shown in Figure 2.5. The structure is based on that used in Law et al. [4], but without the central core. The compartment is $42 \mathrm{~m}$ long, $28 \mathrm{~m}$ wide and $3.6 \mathrm{~m}$ high. There are six structural bays along the length of the building, and four across its width. Each bay is $7.5 \mathrm{~m} \times 7.5 \mathrm{~m}$. The fire is assumed to ignite at one end of the structure, occupy the full width and burn along its length over time as illustrated in Figure 2.5.

A family of fires was investigated with sizes ranging from $1 \%$ to $100 \%$ of the floor plate. A selection of fires is given in Table 2.1, showing the fire size and area, the heat release rate calculated from Eq. (2.1), the maximum total burning duration from Eq. (2.10), and the spread rate from Eq. (2.5).

The burning durations of the larger fire sizes are of the same order of magnitude as those predicted by the traditional methods [2]. The smaller fire sizes have burning durations on the order of those observed in large, accidental fires [7, 8, 9]. For example, the One Meridian Plaza fire in Philadelphia in 1991 lasted for almost 19 hours [29]. The range of spread rates from the family of fires also corresponds well with physical values. Quintiere [30] gives the rough order of magnitude of lateral fire spread on thick solids as $10^{-1} \mathrm{~cm} / \mathrm{s}(0.06 \mathrm{~m} / \mathrm{min})$ and of "forest and urban fire spread" between 1 and $10^{2} \mathrm{~cm} / \mathrm{s}(0.6$ to $60 \mathrm{~m} / \mathrm{min})$. This again highlights the advantage of considering a range of fire sizes in this methodology, as the burning duration and spread rate of an accidental fire cannot be calculated a priori. 
The family of fires created was used to generate transient gas phase temperature fields across the structure. The temperature fields were then used as input to calculate the resulting in-depth concrete temperature at the rebar location as a simple measure of structural performance. The hotter the rebar temperature, the poorer the structural performance is deemed to be. One-dimensional conductive heat transfer inside the material was considered with boundary conditions for convective and radiant heating from the gas phase as well as reradiation. The heat transfer was solved by means of finite differences, as detailed in Appendix A. Law et al. [4] showed that the average rebar temperature across a bay is a more critical parameter for the structural response than that of a single point. Therefore to obtain the bay average rebar temperatures (referred to as the bay temperature), the average across the whole bay is calculated from results of the one-dimensional, in-depth heat transfer method at each node.

An alternative to this approach would be to use a three-dimensional heat transfer method and then calculate the full structural response by use of a detailed Finite Element Model (FEM). This was the approach taken in the work done by Law et al. [4]. For comparison, the bay average temperature results of the method used in this paper were found to be between 7 to $15 \%$ higher than that calculated by Law et al. Therefore this method is deemed appropriate, especially considering the differences in comparison to a FEM approach (one vs. three-dimensional heat transfer, constant vs. temperature dependent concrete properties, and varying heat transfer formulations). The simple approach used here allows for rapid calculation of a large variety of parameters which would be computationally restrictive to do with full FEM analyses.

\subsection{Parameter Sensitivity Study}

One aim of this methodology is to allow fire safety engineers to interface with structural fire engineers to determine the most appropriate design fire scenarios prior to the detailed structural analysis. It is the intent of this sensitivity study to highlight the important parameters that should be considered in design. 
The parameter values for the base case scenario and the ranges investigated are given in Table 2.2. Unless specified otherwise, the base case values are used. The study includes building, physical, and numerical parameters. Building parameters are the actual quantities related to the building structure and its contents. Changes in these parameters come from differing building designs or uses. Physical parameters are those related to the temperature field and heat transfer mechanisms. Numerical parameters are those required to generate the temperature fields and heating but without physical meaning, such as the grid size. These last two sets of parameters do not depend on the building design or its use, but on the theoretical or numerical aspects of the methodology. As the fire size is the fundamental input variable to the methodology, it is not classified as a parameter but a variable.

The following sections present the sensitivity of each of the parameters in Table 2.2.

\subsubsection{Fire Size}

Figure 2.6 shows the variation of peak rebar temperature with fire size from $1.25 \%$ to $100 \%$ for a grid size of $0.2625 \mathrm{~m}$. This grid size was selected as it divides evenly amongst a large number of fire sizes.

Fire sizes between $5 \%$ and $20 \%$ result in the largest bay temperatures (between 538 and $548^{\circ} \mathrm{C}$ ) and thus are the most challenging for the structure. The maximum peak bay temperature is $548^{\circ} \mathrm{C}$ for a $10 \%$ fire. Note that both a very small fire $(2 \%)$ and a very large fire $(100 \%)$ result in the same peak bay temperature of $410^{\circ} \mathrm{C}$. The smaller fire sizes have long durations, but relatively low far field temperatures. The larger fire sizes have higher far field temperatures, but for shorter durations. The maximum rebar temperature found for the $10 \%$ fire size results from an optimum heating balance between far field temperature and duration. These results are similar to conclusions of work previously reported $[4,13]$.

Because the most challenging scenario is the $10 \%$ fire size, it is used as the base case for the rest of this sensitivity study.

\subsubsection{Grid Size}


The grid size was varied in a series of cases to ensure that the number of nodes in the discretisation scheme is high enough to properly resolve the dynamics of the problem. The grid size has an impact on three parts of the methodology: the resolution of the far field temperature in Eq. (2.4), the total burning duration in Eq. (2.9), and the resolution of a bay $\left(L_{b} / \Delta x\right)$. The impacts of these parameters are explored below.

Figure 2.7 shows the error of the peak bay temperature relative to the finest grid against varying grid sizes. The finest grid size used for any calculation was $0.21 \mathrm{~m}$, which is fine enough to include more than one node across the smallest fire size (1\%). The smaller the grid size, the lower the error, thus proving the grid independence of the model. A grid size of $1.05 \mathrm{~m}$ gives an error of approximately $1 \%$ for several fire sizes, including the base case $10 \%$ fire size, and therefore has been selected as the base case grid size.

The evolution of the gas temperature and the resulting bay temperatures for the last bay (Bay 6) at the far end of the structure (node n) are shown in Figure 2.8 for three grid sizes: coarse $(\Delta x=10.5 \mathrm{~m})$, medium $(\Delta x=2.1 \mathrm{~m})$, and fine $(\Delta x=0.21 \mathrm{~m})$. For the course grid, the peak bay temperature was lower (by $63^{\circ} \mathrm{C}$, difference of $12.7 \%$ ) and arrived earlier (by $15 \mathrm{~min}$, difference of $15.6 \%$ ) than for the fine grid which resulted in a peak bay temperature of $514^{\circ} \mathrm{C}$ at $96 \mathrm{~min}$ after ignition. The results of the medium grid are very similar to the fine grid $\left(517^{\circ} \mathrm{C}\right.$ peak bay temperature at $\left.95 \mathrm{~min}\right)$. Given the differences in structural heating resulting from the coarse and fine grids, and the similarities of heating from the medium and fine grids, the model is concluded to be grid independent for grid sizes of $2.1 \mathrm{~m}$ and finer.

The change of slope in the gas phase curves at $19 \mathrm{~min}$ is due to the growth of the fire to its full size prior to that time. Note that these bay temperature results are for the last bay in the compartment. Thus when the fire ends, the gas temperature returns immediately to ambient. After that, the rebar is still heated from the thermal wave passing through the slab but then slowly cools at a rate controlled by the heat transfer in the concrete. This cooling phase and its relationship to whole frame response during a fire are of great importance to structural engineering $[33,34,35]$. 
The more well resolved the compartment, the longer the total burning duration is, eventually approaching $t_{\text {total }}^{*}$ as can been seen from Eqs (2.9) and (2.10). For the gas phase temperatures shown in Figure $2.8, t_{\text {total }}$ is $80 \%$ of the theoretical limit, $t_{\text {total }}^{*}$, for the coarse

grid (a $t_{\text {total }}$ of $76 \mathrm{~min}$ compared to $t_{\text {total }}^{*}$ which is $95 \mathrm{~min}$ ), $96 \%$ for the medium grid ( $t_{\text {total }}$ of $91.2 \mathrm{~min}$ ), and $99.6 \%$ for the fine grid ( $t_{\text {total }}$ of $\left.94.6 \mathrm{~min}\right)$. This is one reason for the earlier and lower peak bay temperature seen for the coarse grid. As an additional check on the impact of this fraction of the theoretical maximum burning duration, one local burning time was added to the coarse grid case (spread evenly amongst the three far field components of the gas phase temperature-time curve), bringing $t_{\text {total }}$ to $95 \mathrm{~min}$ and equal to $t_{\text {total }}^{*}$. The peak bay temperature from this check was $477^{\circ} \mathrm{C}(7.5 \%$ lower than that from the finest grid $)$ at $100 \mathrm{~min}$ (4.2\% later), instead of the previous $451^{\circ} \mathrm{C}$ peak and $15 \mathrm{~min}$ time difference. Thus, the impact of the temporal delay introduced by coarse grids can be easily quantified.

Coarse grids that are on the same order of length as a structural bay could also affect the bay temperatures. This is explored in Section 2.5.4.

\subsubsection{Rebar Depth}

The depth of rebar is a fundamental design variable for any concrete structure. Typical rebar depths are between 20 and $60 \mathrm{~mm}$. A structural engineer would usually establish the rebar depth of a structure before its fire performance is analysed in detail. However, it is worth understanding the impact of rebar depth on peak bay temperatures, as it could make a significant difference in the design and, subsequently, the performance and cost of the structure.

Figure 2.9a shows the gas phase and resulting bay temperature vs. time for various rebar depths for the base case. Figure $2.9 \mathrm{~b}$ shows the peak bay rebar temperature for varying rebar depth and fire size, for a grid size of $0.21 \mathrm{~m}$. The results show the logical result that the shallower the rebar, the higher its temperature.

The $10 \%$ fire size results in the maximum peak bay temperature for all rebar depths except the $50 \mathrm{~mm}$ depth, which has its maximum at the $5 \%$ fire size. This is due to the increased 
importance of the pre-heating and post-heating of the rebar from the far field, which is longer for smaller fires. A rebar depth of $42 \mathrm{~mm}$ is used for the base case as this was the design value for the similar structure in [4].

\subsubsection{Bay Location and Bay Size}

As discussed above, the bay temperature is a critical parameter for structural response. Figure 2.10 shows the sensitivities of the bay location and bay size. Figure 2.10a gives the temperature-time curves for each bay in the compartment (see Figure 2.5 for bay numbering). Figure $2.10 \mathrm{~b}$ gives the peak bay temperature as a function bay length for three fire sizes $(5 \%, 10 \%$, and $25 \%)$. The fire begins in Bay 1 and travels across the structure, eventually ending in Bay 6.

Figure 2.10a shows that the peak bay temperature increases with distance from the ignition location. This is because the peak temperatures are always reached from exposure to the near field, but are also dependent on the bay temperature at the time of near field arrival. The bay temperature at the time the fire arrives is dependent on the exposure duration and temperatures of the far field. As each subsequent bay along the structure is exposed to longer pre-heating times prior to the arrival of the near field, the hottest peak bay temperature is found in the final bay (Bay 6).

This conclusion can be generalised, stating that the peak rebar temperature in a structure will occur at the final burning location of the fire. This is a significant result, as it means that the exact travel path of a fire does not need to be known if the peak rebar temperature is the variable of interest for the structural analysis. This is beneficial for design, as the path cannot be known a priori as there are many possible paths of fire travel depending on ignition location, early fire development and subsequent glazing failure. Thus for design, if the structural engineer can identify particular areas of the structure that are most vulnerable to the effects of elevated rebar temperature, then it can be conservatively assumed that the fire reaches this location last, thereby producing the most onerous fire environment for that part of the structure. Note that other structural variables are important in travelling fires (see [4]) 
and that the role played by the heating and cooling phases, for example, are not directly captured by the peak bay temperature alone.

Figure $2.10 \mathrm{~b}$ shows the impact of bay size on bay temperature. The bay size was varied from $1.05 \mathrm{~m}$ (the smallest possible bay size for the base case grid size, as there is only a single node per bay) to $21 \mathrm{~m}$ (half the length of the structure, which is deemed to be beyond a realistic upper bound). The results indicate that the larger the fire, the less impact the bay size has on the peak bay temperature. This is due to the ratio between fire size and bay size. For bay sizes that are smaller than the fire size, the full bay is exposed to the near field at once. Given that much of the range in bay size variation is less than the fire size for the $25 \%$ case (the largest fire examined here, with $L_{f}=10.5 \mathrm{~m}$ ), little impact on peak temperatures is expected from variation of bay size. However, for the smaller fire sizes, many of the bay lengths examined are greater than the fire lengths $(2.1 \mathrm{~m}$ for the $5 \%$ fire and $4.2 \mathrm{~m}$ for the $10 \%)$. Therefore impact of bay size is to be expected in these cases.

The results also show that the maximum peak bay temperatures occur nearly, but not exactly, when the bay size is equal to the fire size. This is due to the balance of higher far field temperatures prior to the fire arriving and lower far field temperatures after the fire passes. There is a small effect of the grid size on the peak value, but as the temperature differences are small (on the order of $10^{\circ} \mathrm{C}$ ) it is not deemed significant.

\subsubsection{Fuel Load Density and Heat Release Rate per Unit Area}

Eq. (2.2) gives the local burning time as a function of the fuel load density and heat release rate per unit area. The local burning time, in turn, affects the total burning duration. The higher the fuel load, the longer the local burning time and, thus, the longer the total burning duration. The heat release rate per unit area also impacts the burning times. The higher the heat release rate per unit area, the shorter the local burning time and total burning duration of a fire. However, the heat release rate per unit area also has an impact on the total heat release rate for a given fire size and, therefore, the far field temperatures. This means that as it reduces the total fire duration, it also increases the gas phase temperatures to which the structure is exposed. 
The amount of fuel in a building significantly alters the dynamics of a fire. The fuel load varies greatly for building types and guidance exists to provide typical ranges [2]. The base case fuel load was taken as the $80^{\text {th }}$ percentile value for office buildings [19]. The range of values for the sensitivity study varies from sparsely furnished (classroom) to densely loaded (library) spaces according to [2]. The heat release rate per unit area is a fundamental characteristic of a fire. The range selected here corresponds to that measured for a variety of fuels that could be expected in a typical office building [31], but excludes very high values that might be associated with rack storage or other industrial usages. The base case value is taken from [20] and is the same used in earlier work [4].

Figure 2.11 shows the variation of peak bay rebar temperature with fuel load density for heat release rates per unit area of 200,500 , and $800 \mathrm{~kW} / \mathrm{m}^{2}$.

Denser fuel loads result in higher peak bay rebar temperatures. The opposite trend is observed for the heat release rate per unit area, i.e. the lower the heat release rate per unit area, the higher the peak bay rebar temperatures. Both of these trends can be explained by the increase in time that results from in an increase in fuel load or decrease of the heat release rate per unit area. While the total heat release rate increases for a higher heat release rate per unit area, these results suggest that the effect of the reduction in fire duration is more important than the effect of the far field temperature on the structural heating. This is due to the linear relationship between heat release rate per unit area and time and the $2 / 3$ power relationship between heat release rate and far field temperature.

\subsubsection{Heat Transfer}

Because it is difficult to quantify specific values of the overall heat transfer coefficient and emissivity in a fire, the sensitivity of these parameters has been examined here. The convective heat transfer coefficient of the exposed side of the concrete slab was varied from 10 to $100 \mathrm{~W} / \mathrm{m}^{2} \mathrm{~K}$ to represent the bounds typically expected in a compartment fire [44]. The material emissivity was varied from 0.2 to 1 . For typical concrete reradiation at high temperatures, the effective emissivity is likely to be high, but 0.2 has been examined as a 
lower bound. The gases are assumed to have an emissivity equal to 1 , and the material absorptivity is assumed to be equal to the emissivity. The base case values of both heat transfer parameters were taken according to Eurocode 1 guidance [2].

Figure 2.12 plots peak bay temperature against the convective heat transfer coefficient for varying values of emissivity and two rebar depths. A shallow rebar depth $(20 \mathrm{~mm})$ was examined, in addition to the base case value, to include a scenario of reduced importance of the conductive heat transfer.

The results indicate that the peak bay temperatures are only marginally affected by the heat transfer parameters at either of the two rebar depths studied. The lower temperatures that result from the lower emissivities indicate that concrete heating is dominated by radiation in the base case.

\subsubsection{Near Field Temperature}

For the sake of conservatism, the methodology assumes that the near field temperature is the peak flame temperature measured in large fires. The sensitivity to this assumption is studied here. Peak temperatures in small fires have been measured in the range of 800 to $1000^{\circ} \mathrm{C}$ [23], while those in larger compartments have been found to be up to approximately $1200^{\circ} \mathrm{C}$ [24]. The FDS simulations of a localised 147MW fire in a large compartment shown in Figure 2.3 agree with this range and predict peak near field temperatures ranging from 800 to $1050^{\circ} \mathrm{C}$, depending on the ventilation scenario. Therefore the near field temperature has been varied from 800 to $1200^{\circ} \mathrm{C}$, with the base case value at the upper end of the range to account for worst case conditions and overcome uncertainty of the associated with its measurement. Figure 2.13 shows the bay temperature evolution over time for varying near field temperatures at Bays 2 and 6.

The results show that a near field temperature variation of $400^{\circ} \mathrm{C}$ (from 800 to $1200^{\circ} \mathrm{C}$ ) produces a peak bay temperature range of just over $100^{\circ} \mathrm{C}$. The results are similar for both bays. The near field temperature has no impact on the structural heating in the far field region, but does have an important overall effect on the predicted fire resistance of the 
structure. However, given that the design value is taken at the upper end of the physical range, it means results from this methodology can be deemed conservative.

\subsubsection{Steel Structure}

In addition to the base case concrete structure, the heating of a typical steel beam is also examined. The steel beam studied was selected to be representative of typical section sizes used in real buildings. Dimensions of the beam are given in Figure 2.14. The beam has been assessed with three levels of fire protection: unprotected, fire rated to $60 \mathrm{~min}$, and fire rated to $120 \mathrm{~min}$. For quantification of its heating, it is assumed that there is a slab above the top flange of the beam and thus it is only heated on three sides.

The heat transfer to the beam was calculated utilising a lumped mass approach and is given in Appendix A. As such, the heat transfer calculation for the beam can only result in a single temperature, similar to that of the method used for the concrete prior to the average across a bay. Therefore it is assumed that the steel beam is perpendicular to the direction of fire propagation and thus is exposed to the same gas temperature along its full length at any given time. Calculation of the heating of a steel beam exposed to a varying temperature field along its length would require the adoption of a two or three-dimensional heat transfer method. Nonetheless, the single point heat transfer calculations used here provide insight into the differences in heating of the three types of steel beam, as compared to the concrete slab.

Figure 2.15 shows the resultant peak steel temperatures for the three beam types at the far end of the final structural bay (Bay 6) for a grid size of $0.21 \mathrm{~m}$. The fine grid resolution was used to best match the node size to the physical size of the steel beam.

It can be seen that the steel temperatures of the unprotected beam reach the near field temperature for all fire sizes. This is due to the low thermal inertia and high conductivity of the unprotected steel. The protected beam temperatures follow a similar trend to that of the concrete structure. The maximum temperature recorded for the $60 \mathrm{~min}$ rated beam is from a $10 \%$ fire size and for the $120 \mathrm{~min}$ beam from a $5 \%$ fire size. 
Figure 2.16 shows temperature-time curves for the gas phase and steel for all three beam types considered at two different locations in the structure. The unprotected steel temperature follows the gas phase temperature very closely, for the reasons given above. The peak steel temperatures are very similar for both locations, with a slightly higher peak reached for the midpoint of Bay 2 for the $60 \mathrm{~min}$ rated beam. This lack of sensitivity to steel location is different from that observed in concrete (see Figure 2.10a)

\subsection{Comparison to Conventional Methods}

Figure 2.17 compares the bay temperature-time curves resulting from the base case fire scenario with those calculated from the standard fire and two Eurocode parametric temperature-time curves [2]. One parametric temperature-time curve assumes $100 \%$ glass breakage on the façade and the other $25 \%$. The parametric curves use the same thermal properties of concrete (see Appendix A for values) and fuel load density as the base case.

The comparison shows that the base case, which is the most onerous fire size in the family of fires, is a more challenging scenario for the structure in terms of peak bay temperature reached than the two parametric curves. In terms of the peak bay temperature, the travelling fire is equivalent to $106 \mathrm{~min}$ of the standard fire, which is similar to the conclusions of Law et al. [4].

The results presented here should be explored in more detail by a structural engineer, as a travelling fire may result in different structural behaviour than that captured by the peak bay temperature alone. For example, whole frame behaviour resulting from exposure to a travelling fire with portions of the structure heating while other areas are cooling may be different than the bay average results suggest here.

\subsection{Final Remarks}


Comparison of the relative impact of all the parameters varied in the methodology is shown in Figure 2.18. The percentage variation of each parameter from the corresponding base case value has been plotted against the resultant percentage change of the peak bay temperature calculated. Figure 2.18a shows the results for the building parameters, and Figure 2.18b the physical and numerical parameters. Fire size has been shown on both plots as it is the main variable in this methodology.

Steeper slopes on the curves in Figure 2.18 correspond to the more sensitive parameters. Positive values in the bay temperature change mean conditions are more onerous on the structure than the base case and negative values less onerous. The largest changes in bay temperature come from rebar depth, fuel load density, fire size, and near field temperature, in this order. These are the most sensitive parameters.

The rebar depth, the most sensitive parameter, is likely to be a fixed value early in the design, but its sensitivity is worth noting for the design process of a building. The exact fuel load density cannot be known, as it is inherently variable and may change over the lifetime of a building. Therefore a reasonable assessment of the likely values should be made during design. It is noted that both of these parameters are related to any form of structural fire assessment, whether that be the travelling fires methodology presented in this paper or the conventional methods.

Fire size is the main variable of this methodology, so the full range should always be explored in a design case. While the near field temperature has a marked impact on the bay temperatures, it is not necessary to vary this parameter for design, as the methodology assumes the most onerous condition.

The methodology presented in this paper offers a paradigm shift in defining fire scenarios for structural fire engineering and compliments the traditional methods. This paper has explored the details of the method and concluded on the more sensitive parameters that ought to be considered in design. The methodology provides a robust platform for 
collaboration between fire engineers and structural fire engineers to jointly understand a building's structural performance in fire.

\section{Acknowledgements}

The authors would like to thank Prof Jose L. Torero for helping to plant the seeds of this research through early discussions. In addition the input of structural engineers Dr Angus Law and Dr Martin Gillie in the valuable collaboration that helped shape this work is gratefully acknowledged. J. Stern-Gottfried thanks Arup for the support of this research and G. Rein the Research Fellowship provided by RAEng/Leverhulme Trust during 2010/2011.

\section{References}

1 Babrauskas, V. and Williamson R.B., "The historical basis of fire resistance testing Part II." Fire Technology, 14(4) 1978, pp. 304-316.

2 Eurocode 1: Actions on structures - Part 1-2: General actions - Actions on structures exposed to fire, European standard EN 1991-1-2, 2002. CEN, Brussels.

3 Stern-Gottfried, J., Chapter 3 in: Travelling Fires for Structural Design, PhD Thesis, School of Engineering, University of Edinburgh, 2011.

4 Law, A., Stern-Gottfried, J., Gillie, M., and Rein, G., “The influence of travelling fires on a concrete frame", Engineering Structures, Vol. 33, 2011, pp. 1635-1642.

doi:10.1016/j.engstruct.2011.01.034. Open access version at: http://www.era.lib.ed.ac.uk/handle/1842/4907

5 Jonsdottir, A. and Rein, G. “Out of Range”, Fire Risk Management, Dec 2009, pp. 14-17. http://www.era.lib.ed.ac.uk/handle/1842/3204

6 Gann, R.G. et al, "Reconstruction of the Fires in the World Trade Center Towers", NIST NCSTAR 1-5, September 2005.

7 McAllister, T.P. et al, “Structural Fire Response and Probably Collapse Sequence of the World Trade Center Building 7", NIST NCSTAR 1-9, November 2008.

8 Fletcher, I. et al, "Model-Based Analysis of a Concrete Building Subjected to Fire," Advanced Research Workshop on Fire Computer Modelling, Santander, Spain, 2007. 
9 Zannoni, M. et al, "Brand bij Bouwkunde", COT Instituut voor Veilingheids - en Crisismanagement, December 2008.

10 Thomas, I.R. and Bennets, I.D., "Fires in Enclosures with Single Ventilation Openings Comparison of Long and Wide Enclosures", The 6th International Symposium on Fire Safety Science, Poitiers, France, 1999.

11 Kirby, B.R. , Wainman, D. E., Tomlinson, L. N., Kay, T. R., and Peacock, B. N., “Natural Fires in Large Scale Compartments", British Steel, 1994.

12 Stern-Gottfried, J., Rein, G., Bisby, L.A., Torero, J.L., “Experimental review of the homogeneous temperature assumption in post-flashover compartment fires". Fire Safety Journal, 45, 2010, pp. 249-261.

13 Jonsdottir, A.M., Stern-Gottfried, J., Rein, G., “Comparison of Resultant Steel Temperatures using Travelling Fires and Traditional Methods: Case Study for the Informatics Forum Building". The 12th International Interflam Conference. Nottingham, UK, 2010.

14 Buchanan, A., "The Challenges of Predicting Structural Performance in Fires", The 9th International Symposium on Fire Safety Science. Karlsruhe, Germany, 2008.

15 Law, A., Stern-Gottfried, J., Gillie, M., and Rein, G., “Structural Engineering and Fire Dynamics: Advances at the Interface and Buchanan's Challenge", The 10th International Symposium on Fire Safety Science, University of Maryland, USA, 2011.

16 Majdalani, A.H. and Torero, J.L., "Compartment Fire Analysis for Modern Infrastructure", $1^{\underline{0}}$ Congresso Ibero-Latino-Americano sobre Segurança contra Incêndio, Natal, Brazil, 2011.

17 Rein, G. et al, "Multi-story Fire Analysis for High-Rise Buildings,” The 11th International Interflam Conference, London, UK 2007. http://www.era.lib.ed.ac.uk/handle/1842/1980

18 Stern-Gottfried, J., Rein, G., Lane, B., and Torero, J. L., “An innovative approach to design fires for structural analysis of non-conventional buildings: A case study," Application of Structural Fire Engineering, Prague, Czech Republic, 2009, http://eurofiredesign.fsv.cvut.cz/Proceedings/1st session.pdf

19 PD 6688-1-2:2007, Background Paper to the UK National Annex to BS EN 1991-1-2.

20 TM19, "Relationships for Smoke Control”, CIBSE, 1995 
21 Walton, W.D. and Thomas, P.H., "Estimating Temperatures in Compartment Fires", Chapter 3-6 of the SFPE Handbook of Fire Protection Engineering, 3rd Edition, 2002.

22 Harmathy, T.Z., "A New Look at Compartment Fires, Part II", Fire Technology, Vol. 8 No. 4, 1972, pp.326-351, doi:10.1007/BF02590537.

23 Audoin, L., Kolb, G., Torero, J.L., and Most, J.M.. “Average centreline temperatures of a buoyant pool fire obtained by image processing of video recordings", Fire Safety Journal, Vol. 24, 1995, pp. 167-187. doi:10.1016/0379-7112(95)00021-K.

24 Drysdale, D., An Introduction to Fire Dynamics, 2nd Edition, John Wiley \& Sons, 1999.

25 Heskestad, G., "Fire Plumes, Flame Height, and Air Entrainment”, Chapter 2-1 of the SFPE Handbook of Fire Protection Engineering, 3rd Edition, 2002.

26 Alpert, R.L., “Calculation of Response Time of Ceiling-Mounted Fire Detectors”, Fire Technology, Vol. 8, 1972, pp. 181-195.

27 Alpert, R.L., "Ceiling Jet Flows", Chapter 2-2 of the SFPE Handbook of Fire Protection Engineering, 3rd Edition, 2002.

28 Clifton, G.C., “Fire Models for Large Firecells”, HERA Report R4-83, 1996, with proposed changes in HERA Steel Design and Construction Bulletin Issue No 54, February 2000 and updates to referenced documents, September 2008.

29 Routley, J.G., Jennings, C., and Chubb, M., “Highrise Office Building Fire, One Meridian Plaza, Philadelphia, Pennsylvania", U.S. Fire Administration Technical Report 049.

30 Quintiere, J.G, "Surface Spread of Flame", Chapter 2-12 of the SFPE Handbook of Fire Protection Engineering, 3rd Edition, 2002.

31 Karlsson, B., and Quintiere, J.G., Enclosure Fire Dynamics. CRC Press, 1999.

32 Jowsey, A., Fire Imposed Heat Fluxes for Structural Analysis. PhD thesis, School of Engineering, The University of Edinburgh, 2006, http://www.era.lib.ed.ac.uk/handle/1842/1480.

33 Bailey, C.G., Burgess, I.W., and Plank, R.J., "Analyses of the Effects of Cooling and Fire Spread on Steel-framed Buildings". Fire Safety Journal, Vol. 26, 1996, pp. 273-293.

34 El Rimawi, J.A., Burgess, I.W., and Plank, R.J., “The Treatment of Strain Reversal in Structural Members during the Cooling Phase of a Fire". Journal of Constructional Steel Research, Vol. 37, 1996, p115-135. 
35 Röben, C., The effect of cooling and non-uniform fires on structural behaviour. PhD thesis, School of Engineering, The University of Edinburgh, 2006.

36 Incropera, F., DeWitt, D., Bergman, T., and Lavine, A., Fundamentals of Heat and Mass Transfer, John Wiley \& Sons, 2007.

37 Buchanan, A., Structural Design for Fire Safety. John Wiley \& Sons, 2002. 


\section{Appendix A: Heat Transfer Calculations}

This appendix provides the details of the simplified heat transfer calculations used to quantify the rebar and steel temperatures.

\section{A.1 Concrete Temperature}

To determine the in-depth temperature of the concrete, a one-dimensional finite-difference approach to the heat conduction equation was taken in explicit form, as given by Incropera et al. [36]. It is assumed that the rebar of the concrete is the same temperature as the adjacent concrete.

The formulation from Incropera et al. only includes surface convection, so a radiative term was added for the surface nodes. This gives Eq. (A.1) for calculating the exposed surface node temperature, and Eq. (A.2) for the interior nodes, and Eq. (A.3) for the backside surface node.

$$
\begin{aligned}
& T_{0}^{t+1}=\frac{2 \Delta t}{\rho_{c} c_{c} \Delta z}\left[h_{0}\left(T_{g}-T_{0}^{t}\right)+\sigma \varepsilon\left(T_{g}^{4}-T_{0}^{t^{4}}\right)+\frac{k_{c}}{\Delta z}\left(T_{1}^{t}-T_{0}^{t}\right)\right]+T_{0}^{t} \\
& T_{i}^{t+1}=F o\left(T_{i+1}^{t}+T_{i-1}^{t}\right)+\left(1-2 F_{o}\right) T_{i}^{t} \\
& T_{n}^{t+1}=\frac{2 \Delta t}{\rho_{c} c_{c} \Delta z}\left[h_{n}\left(T_{\infty}-T_{n}^{t}\right)+\sigma \varepsilon\left(T_{\infty}^{4}-T_{n}^{t^{4}}\right)+\frac{k_{c}}{\Delta z}\left(T_{n-1}^{t}-T_{n}^{t}\right)\right]+T_{n}^{t}
\end{aligned}
$$

where $T_{i}^{t}$ is the concrete temperature at time $\mathrm{t}$, and location $\mathrm{i}(\mathrm{K})$ - a subscript of 0 indicates the exposed surface and a subscript of $n$ the backside surface.

$T_{g}$ is the gas temperature $(\mathrm{K})$

$T_{\infty}$ is the ambient temperature $(293.15 \mathrm{~K})$

$\rho_{c}$ is the density of concrete $\left(2300 \mathrm{~kg} / \mathrm{m}^{3}\right)$

$c_{c}$ is the specific heat of concrete $(1000 \mathrm{~J} / \mathrm{kg} \mathrm{K})$ 
$h$ is the convective heat transfer coefficient $\left(35 \mathrm{~W} / \mathrm{m}^{2} \mathrm{~K}\right.$ for the exposed surface and $4 \mathrm{~W} / \mathrm{m}^{2} \mathrm{~K}$ for the backside surface [2])

$\sigma$ is the Stefan-Boltzmann constant $\left(5.67 \times 10^{-8} \mathrm{~W} / \mathrm{m}^{2} \mathrm{~K}^{4}\right)$

$\varepsilon$ is the radiative and reradiative emissivity of the material and gas combined (varied)

$k_{c}$ is the thermal conductivity of concrete $(1.3 \mathrm{~W} / \mathrm{mK})$

$\Delta t$ is the time step (10s)

$\Delta z$ is the element length $(0.01 \mathrm{~m})$

Fo is the Fourier number (-), given in Eq. (A.4)

$$
F o=\frac{k_{c} \Delta t}{\rho_{c} c_{c} \Delta z^{2}}
$$

The time step and element length were selected to meet the stability criteria highlighted by Incropera et al. The concrete material properties were taken from Buchanan [37] for calcareous concrete.

\section{A.2 Unprotected Steel Beam Temperature}

The unprotected steel beam temperatures were calculated by a lumped mass heat transfer method, as given by Buchanan [37], and shown below.

$$
\Delta T_{s}=\frac{H_{p}}{A} \frac{1}{\rho_{s} c_{s}}\left[h_{c}\left(T_{g}-T_{s}\right)+\sigma \varepsilon\left(T_{g}^{4}-T_{s}^{4}\right)\right] \Delta t
$$

where $T_{s}$ is the steel temperature $(\mathrm{K})$

$T_{g}$ is the gas temperature $(\mathrm{K})$

$H_{p}$ is the heated perimeter of the beam $(1.284 \mathrm{~m})$

$A$ is the cross section of the beam $\left(0.00856 \mathrm{~m}^{2}\right)$

$\rho_{s}$ is the density of steel $\left(7850 \mathrm{~kg} / \mathrm{m}^{3}\right)$

$c_{S}$ is the temperature dependent specific heat of steel $(\mathrm{J} / \mathrm{kgK})$

$h_{c}$ is the convective heat transfer coefficient $\left(35 \mathrm{~W} / \mathrm{m}^{2} \mathrm{~K}\right)$

$\sigma$ is the Stefan-Boltzmann constant $\left(5.67 \times 10^{-8} \mathrm{~W} / \mathrm{m}^{2} \mathrm{~K}^{4}\right)$ 
$\varepsilon$ is the radiative and reradiative emissivity of the material and gas combined (0.7) $\Delta t$ is the time step (10s)

All constants and steel material properties (except the emissivity) are taken from Buchanan, including the temperature dependent specific heat.

\section{A.3 Protected Steel Beam Temperature}

The protected beam temperature calculation was also taken from Buchanan [37] and is given below.

$$
\Delta T_{s}=\frac{H_{p}}{A} \frac{k_{i}}{d_{i} \rho_{s} c_{s}} \frac{\rho_{s} c_{s}}{\left[\rho_{s} c_{s}+\left(H_{p} / A\right) d_{i} \rho_{i} c_{i} / A\right]}\left(T_{g}-T_{s}\right) \Delta t
$$

where $k_{i}$ is the thermal conductivity of the insulation $(0.12 \mathrm{~W} / \mathrm{m} \mathrm{K})$

$d_{i}$ is the thickness of the insulation (m)

$\rho_{i}$ is the density of the insulation $\left(550 \mathrm{~kg} / \mathrm{m}^{3}\right)$

$c_{i}$ is the specific heat of the insulation $(1200 \mathrm{~J} / \mathrm{kg} \mathrm{K})$

The material properties of the insulation were based on high density perlite, as given by Buchanan. The thickness of the insulation was solved for using Eq. (A.6), applying the standard temperature-time curve and limiting the steel temperature to below $550^{\circ} \mathrm{C}$ for 60 and 120 minutes. This method should ensure a similar level of performance for any insulating material used to achieve these fire ratings. 


\begin{tabular}{|l|l|l|l|l|}
\hline Fire size & $\boldsymbol{A}_{\boldsymbol{f}}\left(\mathbf{m}^{\mathbf{2}}\right)$ & $\dot{\boldsymbol{Q}}(\mathbf{M W})$ & $\boldsymbol{t}_{\text {total }}^{*}(\mathrm{~min})$ & $\boldsymbol{s}(\mathbf{m} / \mathbf{m i n})$ \\
\hline $1 \%$ & 11.8 & 5.9 & 1919 & 0.02 \\
\hline $2.5 \%$ & 29.4 & 14.7 & 779 & 0.06 \\
\hline $5 \%$ & 58.8 & 29.4 & 399 & 0.11 \\
\hline $10 \%$ & 117.6 & 58.8 & 209 & 0.22 \\
\hline $25 \%$ & 294 & 147 & 95 & 0.55 \\
\hline $50 \%$ & 588 & 294 & 57 & 1.11 \\
\hline $75 \%$ & 882 & 441 & 44.3 & 1.66 \\
\hline $100 \%$ & 1176 & 588 & 38 & 2.21 \\
\hline
\end{tabular}

Table 2.1: A selection from the family of fires. 


\begin{tabular}{|c|c|c|c|c|}
\hline Parameter & Range & Base Case & $\begin{array}{l}\text { Parameter } \\
\text { Type }\end{array}$ & Comment \\
\hline $\begin{array}{l}\text { Fire Size } \\
\left(A_{f}\right)\end{array}$ & $\begin{array}{l}1 \%-100 \% \text { of } \\
\text { floor plate }\end{array}$ & $10 \%$ & $\begin{array}{l}\text { Main } \\
\text { variable }\end{array}$ & $\begin{array}{l}\text { Range is parametrically generated to } \\
\text { cover all possibilities. Base case value } \\
\text { determined by analysis in Section 2.5.1. }\end{array}$ \\
\hline Grid Size $(\Delta x)$ & $0.21-42 m$ & $1.05 \mathrm{~m}$ & Numerical & $\begin{array}{l}\text { Range is to have a well resolved grid for } \\
\text { the smallest fire }(1 \%) \text { to the coarsest } \\
\text { possible for the largest fire ( } 100 \%) \text {. Base } \\
\text { case value determined by analysis in } \\
\text { Section } 2.5 .2 \text {. }\end{array}$ \\
\hline $\begin{array}{l}\text { Rebar Depth } \\
\left(d_{r}\right)\end{array}$ & $20-50 \mathrm{~mm}$ & $42 \mathrm{~mm}$ & Building & $\begin{array}{l}\text { Range taken to be representative of } \\
\text { typical range in real buildings. Base case } \\
\text { value as per the design of the case study } \\
\text { building [4]. }\end{array}$ \\
\hline Bay Location & $1^{\text {st }}-6^{\text {th }}$ bay & $6^{\text {th }}$ bay & Building & $\begin{array}{l}\text { Range is all six bays of the structure. Base } \\
\text { case value selected as it is the most } \\
\text { onerous for the structure as shown in } \\
\text { Section 2.5.4. }\end{array}$ \\
\hline $\begin{array}{l}\text { Bay Size } \\
\left(L_{b}\right)\end{array}$ & $1.05-21 \mathrm{~m}$ & $7 \mathrm{~m}$ & Building & $\begin{array}{l}\text { Range is from the bay being the base case } \\
\text { grid size }(1.05 \mathrm{~m}) \text { to half the structure's } \\
\text { length }(21 \mathrm{~m}) \text {. Base case value as per the } \\
\text { design of the case study building [4]. }\end{array}$ \\
\hline $\begin{array}{l}\text { Fuel Load } \\
\text { Density } \\
\left(q_{f}\right)\end{array}$ & $\begin{array}{l}285- \\
1500 \mathrm{MJ} / \mathrm{m}^{2}\end{array}$ & $570 \mathrm{MJ} / \mathrm{m}^{2}$ & Building & $\begin{array}{l}\text { Range covers sparsely furnished } \\
\text { (classroom) to densely loaded (library) } \\
\text { spaces. Base case value is taken as the } 80^{\text {th }} \\
\text { percentile design value [19] for office } \\
\text { buildings. }\end{array}$ \\
\hline $\begin{array}{l}\text { HRR per Unit } \\
\text { Area }\left(\dot{Q}^{\prime \prime}\right)\end{array}$ & $\begin{array}{l}200- \\
800 \mathrm{~kW} / \mathrm{m}^{2}\end{array}$ & $500 \mathrm{~kW} / \mathrm{m}^{2}$ & Building & $\begin{array}{l}\text { Range taken for representative values of } \\
\text { real fuels in a non-industrial building } \\
\text { [31]. Base case value is taken as densely } \\
\text { furnished office [20]. }\end{array}$ \\
\hline Emissivity $(\varepsilon)$ & $0.2-1$ & 0.7 & Physical & $\begin{array}{l}\text { Range taken to test sensitivity; however } \\
\text { values in an accidental fire are expected } \\
\text { to be above } 0.5 \text {. Base case value is taken } \\
\text { from Eurocode guidance [2]. }\end{array}$ \\
\hline $\begin{array}{l}\text { Convective } \\
\text { Coefficient } \\
\left(h_{c}\right) \\
\end{array}$ & $\begin{array}{l}10- \\
100 \mathrm{~W} / \mathrm{m}^{2} \mathrm{~K}\end{array}$ & $35 \mathrm{~W} / \mathrm{m}^{2} \mathrm{~K}$ & Physical & $\begin{array}{l}\text { Range taken to represent bounds in a fire } \\
\text { condition [32]. Base case value is taken } \\
\text { from Eurocode guidance [2]. }\end{array}$ \\
\hline $\begin{array}{l}\text { Near Field } \\
\text { Temperature } \\
\left(T_{n f}\right)\end{array}$ & $800-1200^{\circ} \mathrm{C}$ & $1200^{\circ} \mathrm{C}$ & Physical & $\begin{array}{l}\text { Range taken to represent bounds of } \\
\text { compartment flame temperatures [23, } \\
24] \text {. The base case is taken as the upper } \\
\text { end of the range to represent worst case } \\
\text { conditions and provide similarity to } \\
\text { earlier work [4]. }\end{array}$ \\
\hline $\begin{array}{l}\text { Structural } \\
\text { Material }\end{array}$ & $\begin{array}{l}\text { Concrete or } \\
\text { Steel }\end{array}$ & Concrete & Building & $\begin{array}{l}\text { Two structure types have been } \\
\text { considered: concrete and steel. This paper } \\
\text { predominately focuses on concrete, but } \\
\text { some comparison is made for three steel } \\
\text { beams: unprotected, } 60 \mathrm{~min} \text { fire rated, and } \\
120 \mathrm{~min} \text { fire rated. }\end{array}$ \\
\hline
\end{tabular}

Table 2.2: $\quad$ Parameter values for the base case and ranges investigated. 


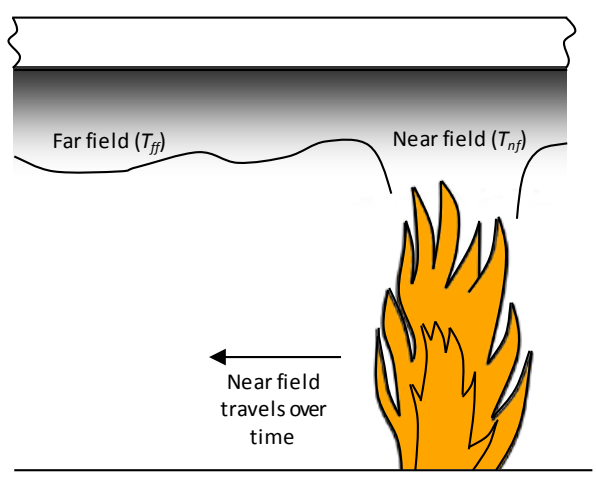

(a)

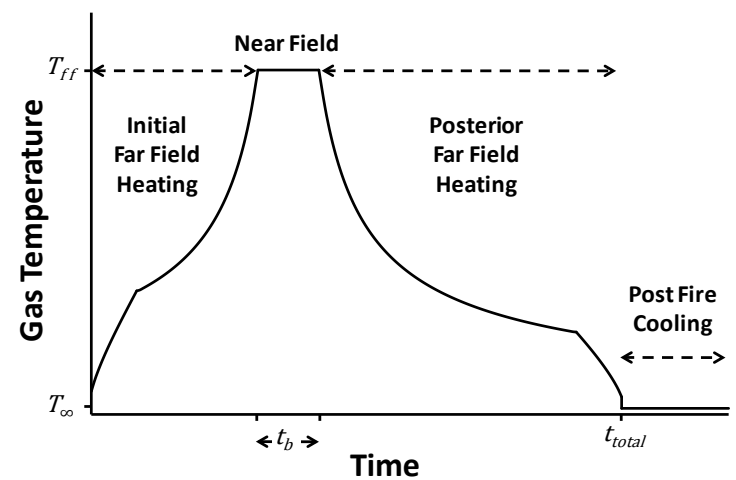

(b)

Figure 2.1: (a) Illustration of a travelling fire; (b) Near field and far field exposure durations at an arbitrary point within the fire compartment. 


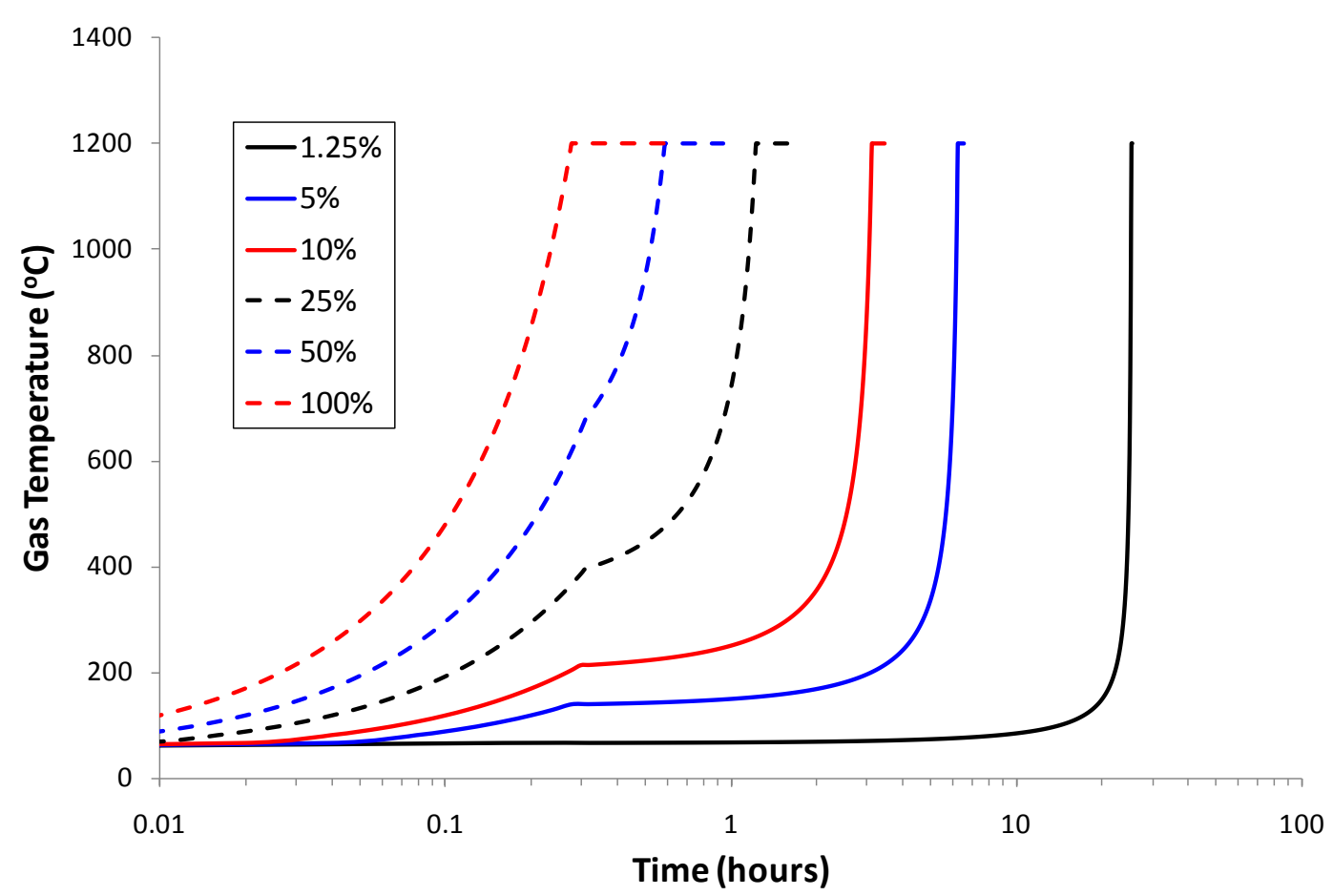

Figure 2.2: Temperature-time curves on a $\log x$-axis for a family of fires at the final location along the fire path. Cooling to ambient temperature starts after the last point in each curve. 


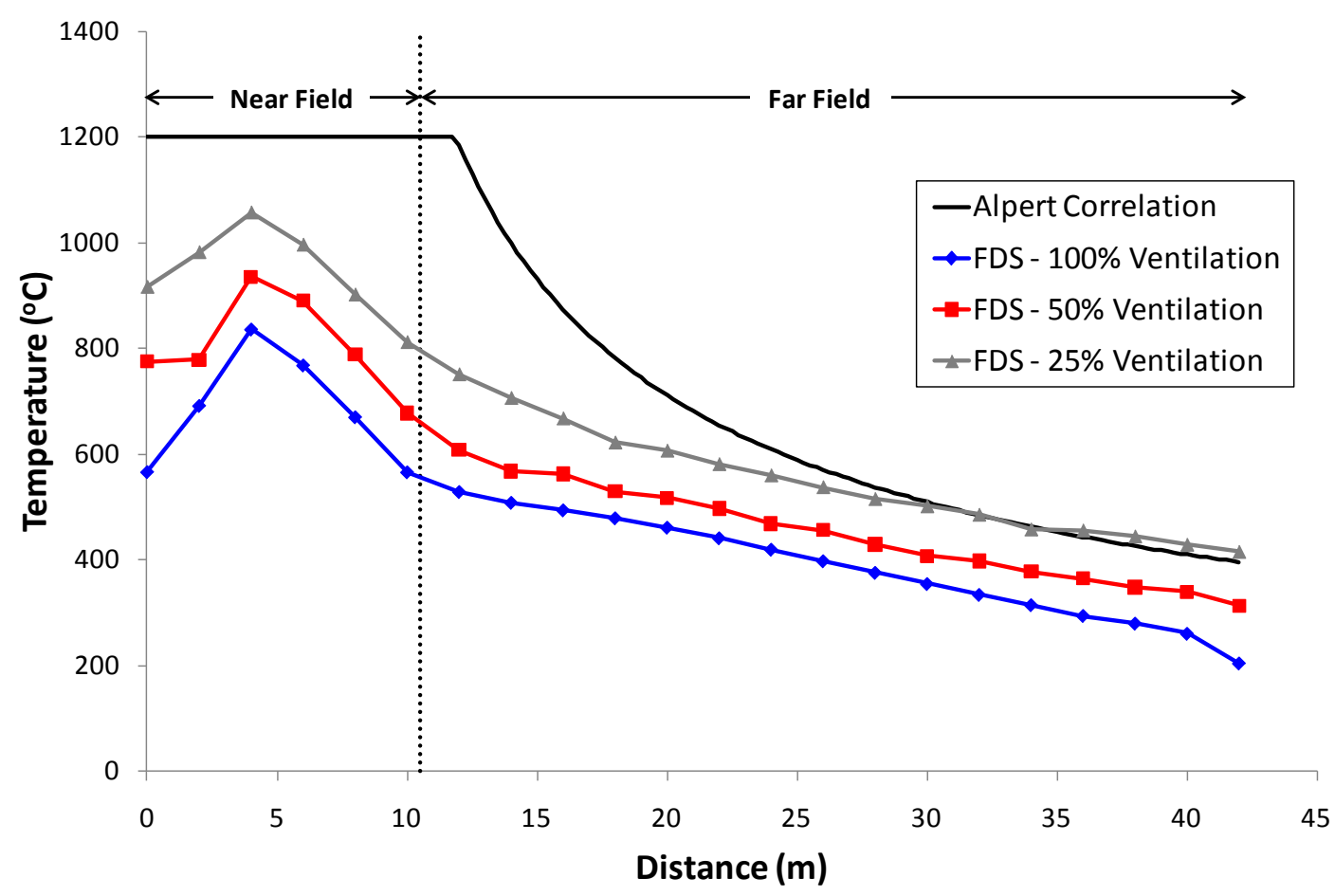

Figure 2.3: Comparison of Alpert's ceiling jet correlation with three FDS models of varying ventilation for a $147 \mathrm{MW}, 28 \mathrm{~m}$ wide fire ( $25 \%$ fire size) burning at one end of the compartment (see Section 2.4 for details). 


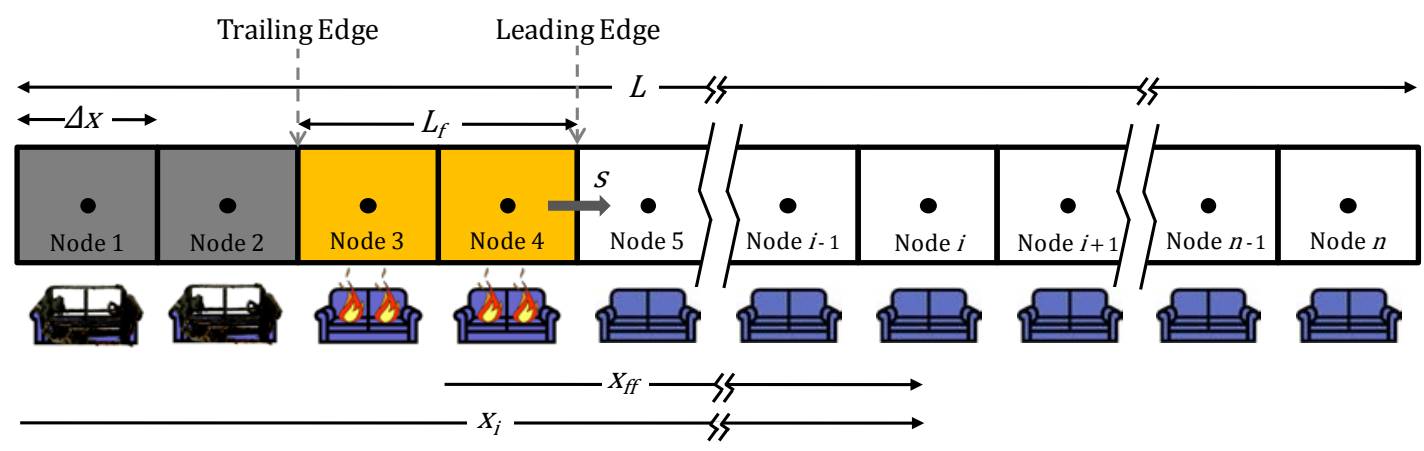

Figure 2.4: Illustration of spatial discretisation, showing the nodes of grid size, $\Delta x$, and the characteristic lengths of the problem. The fire (orange) travels at spread rate, $s$, towards the unburnt nodes (white), leaving burnt-out nodes (grey) behind. 


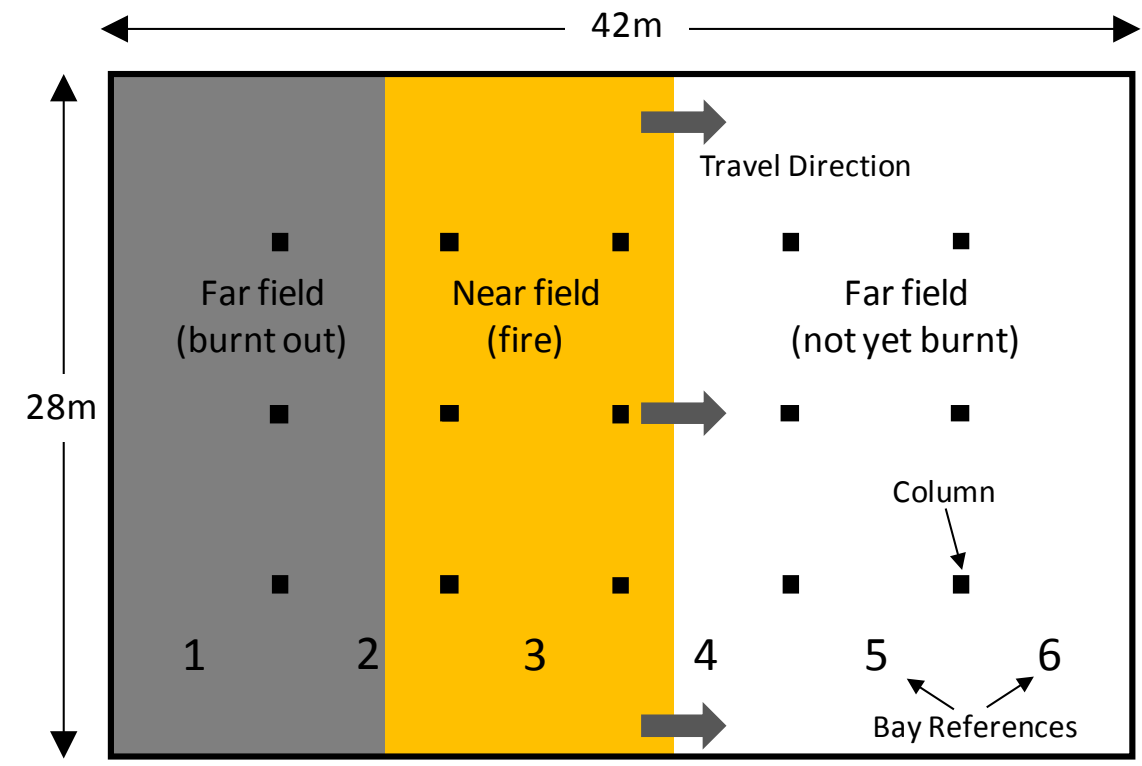

Ignition at this side

Figure 2.5: The generic concrete structure used for the case study. 


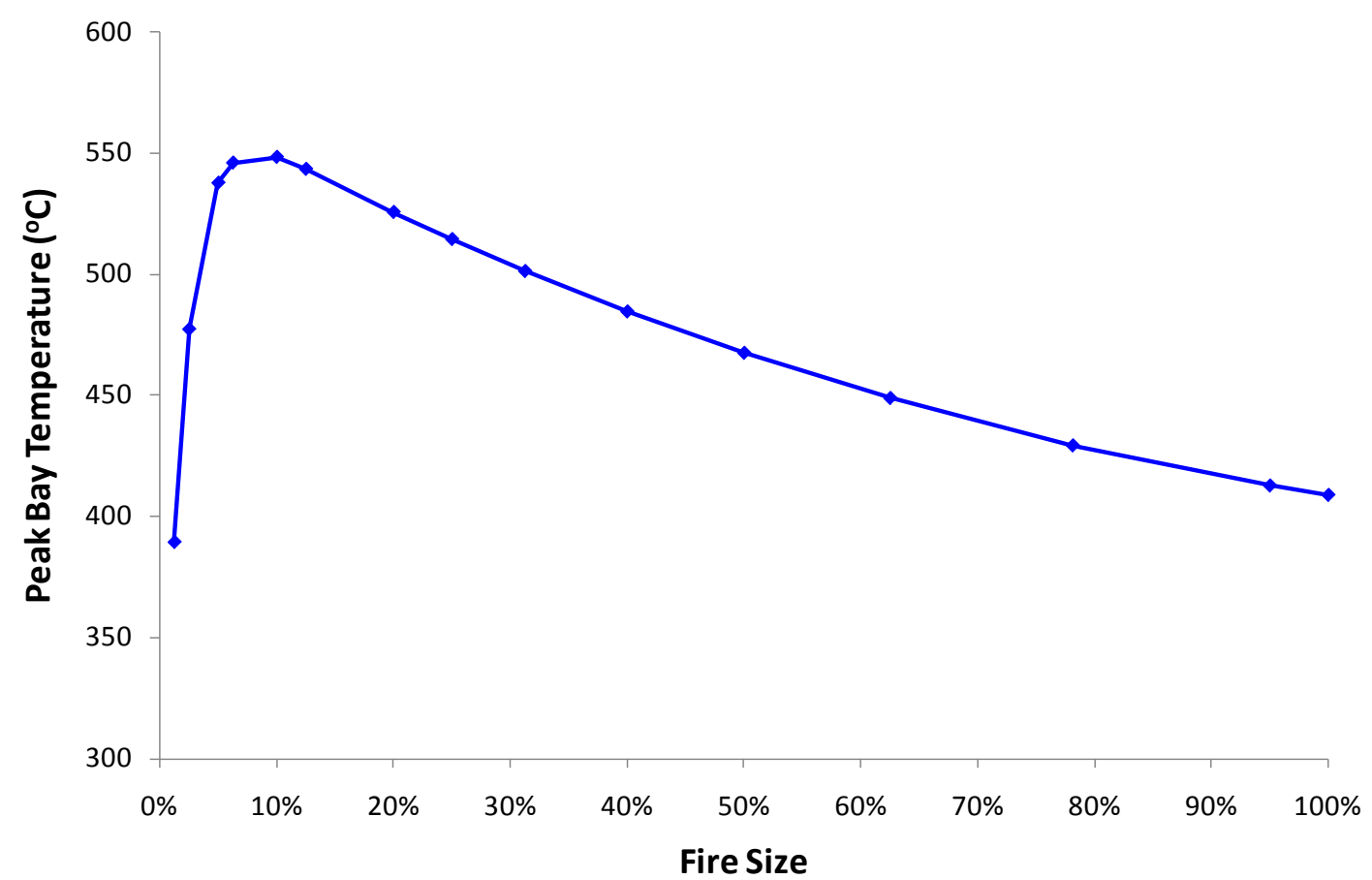

Figure 2.6: Peak bay temperatures vs. fire size for $\Delta x=0.2625 \mathrm{~m}$. 


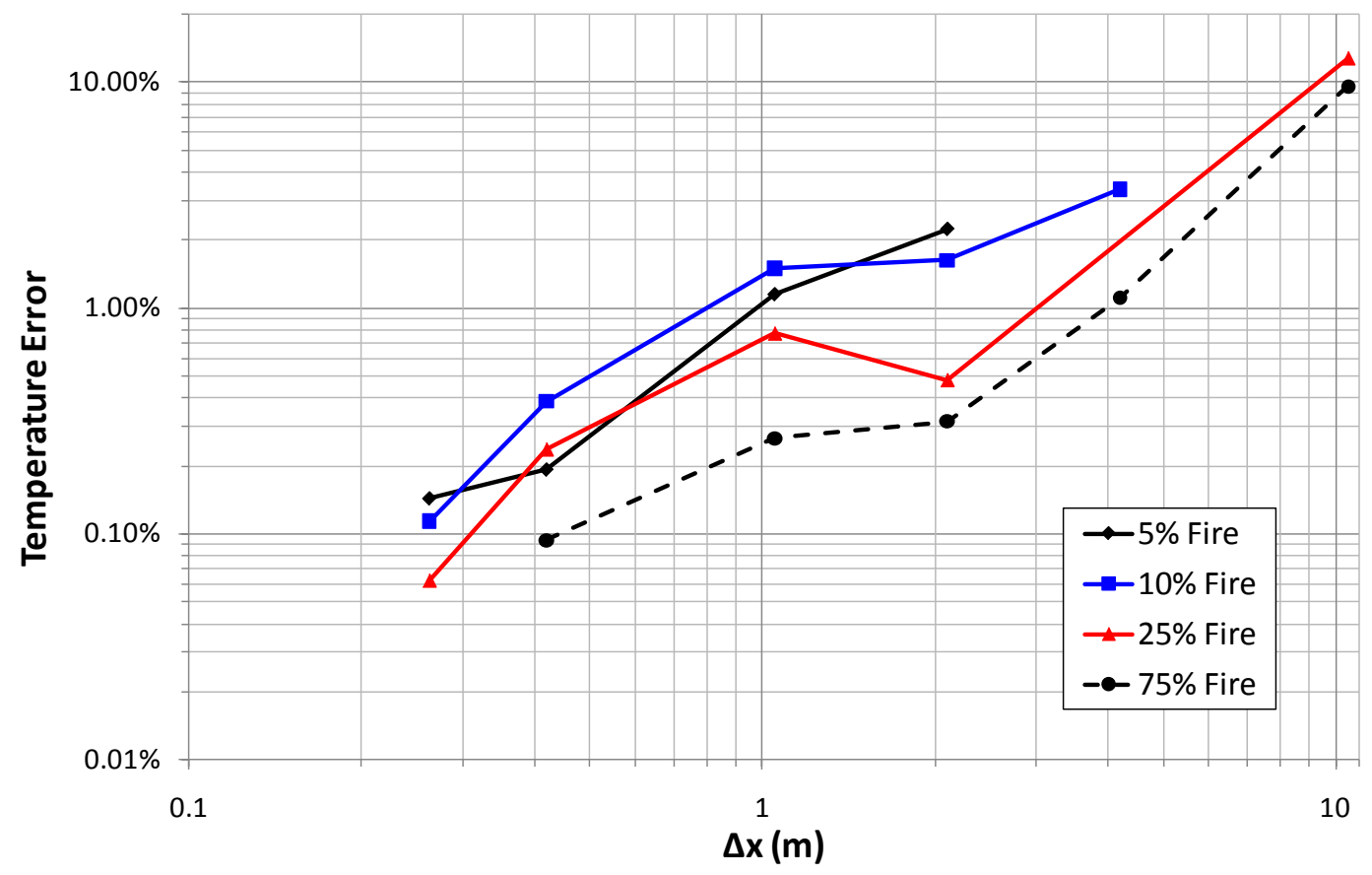

Figure 2.7: Error in the peak bay temperature relative to finest grid $(\Delta x=0.21 \mathrm{~m})$ vs. grid size for a range of fire sizes. 


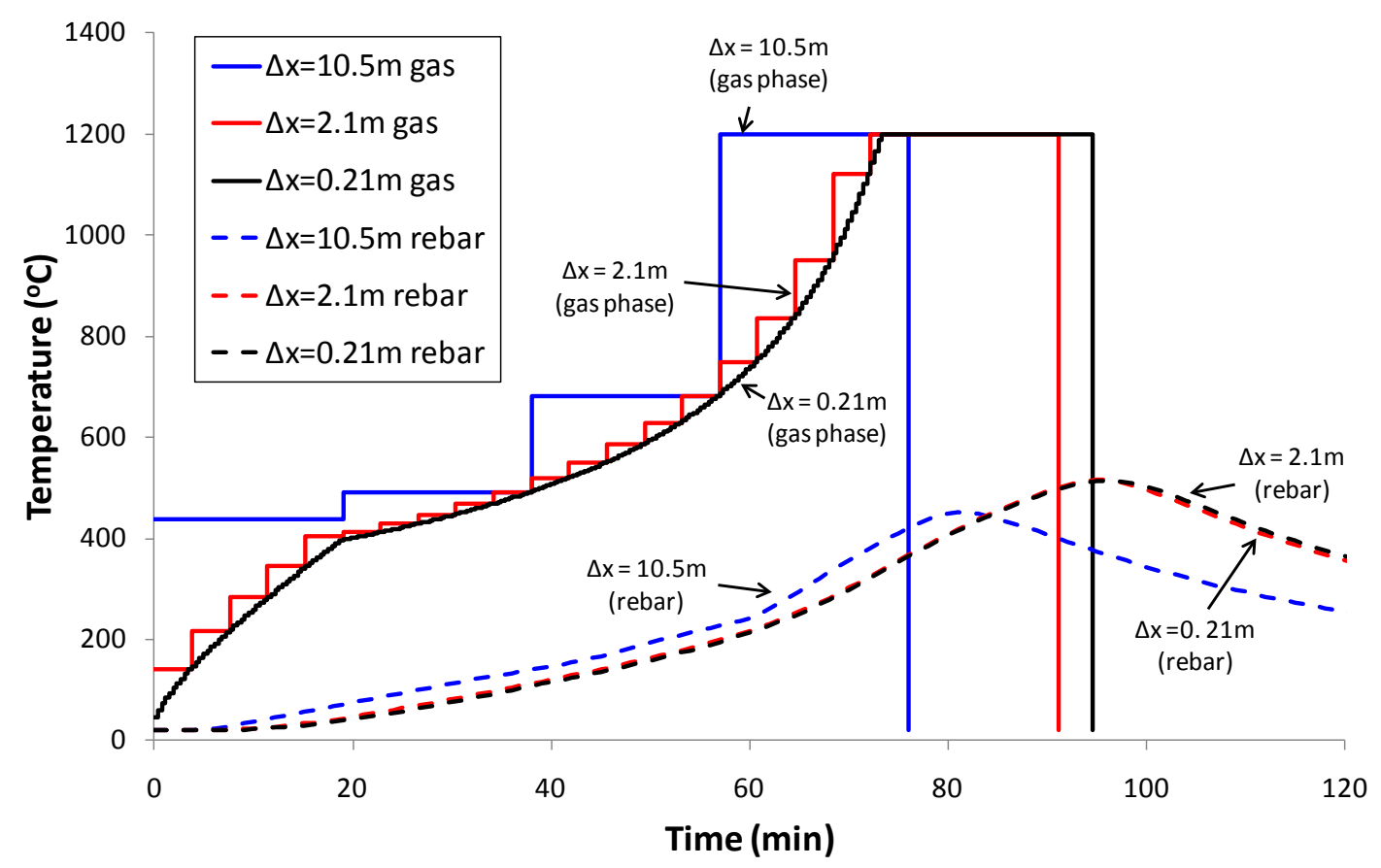

Figure 2.8: Gas phase and resulting bay temperatures vs. time at the far end of the structure (Bay 6) for coarse $(\Delta x=10.5 \mathrm{~m})$, medium $(\Delta x=2.1 \mathrm{~m})$, and fine $(\Delta x=0.21 \mathrm{~m})$ grids. 


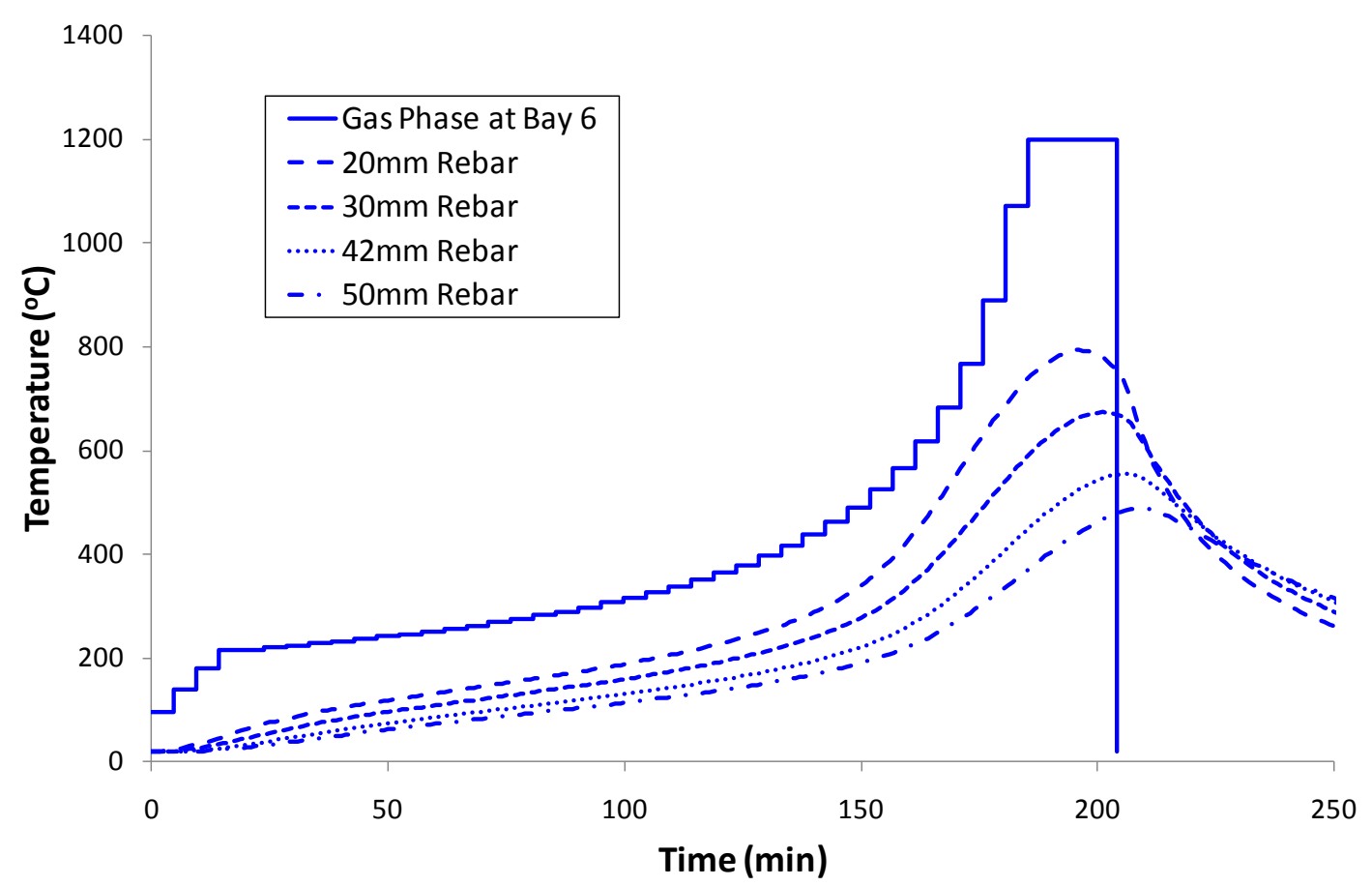

(a)

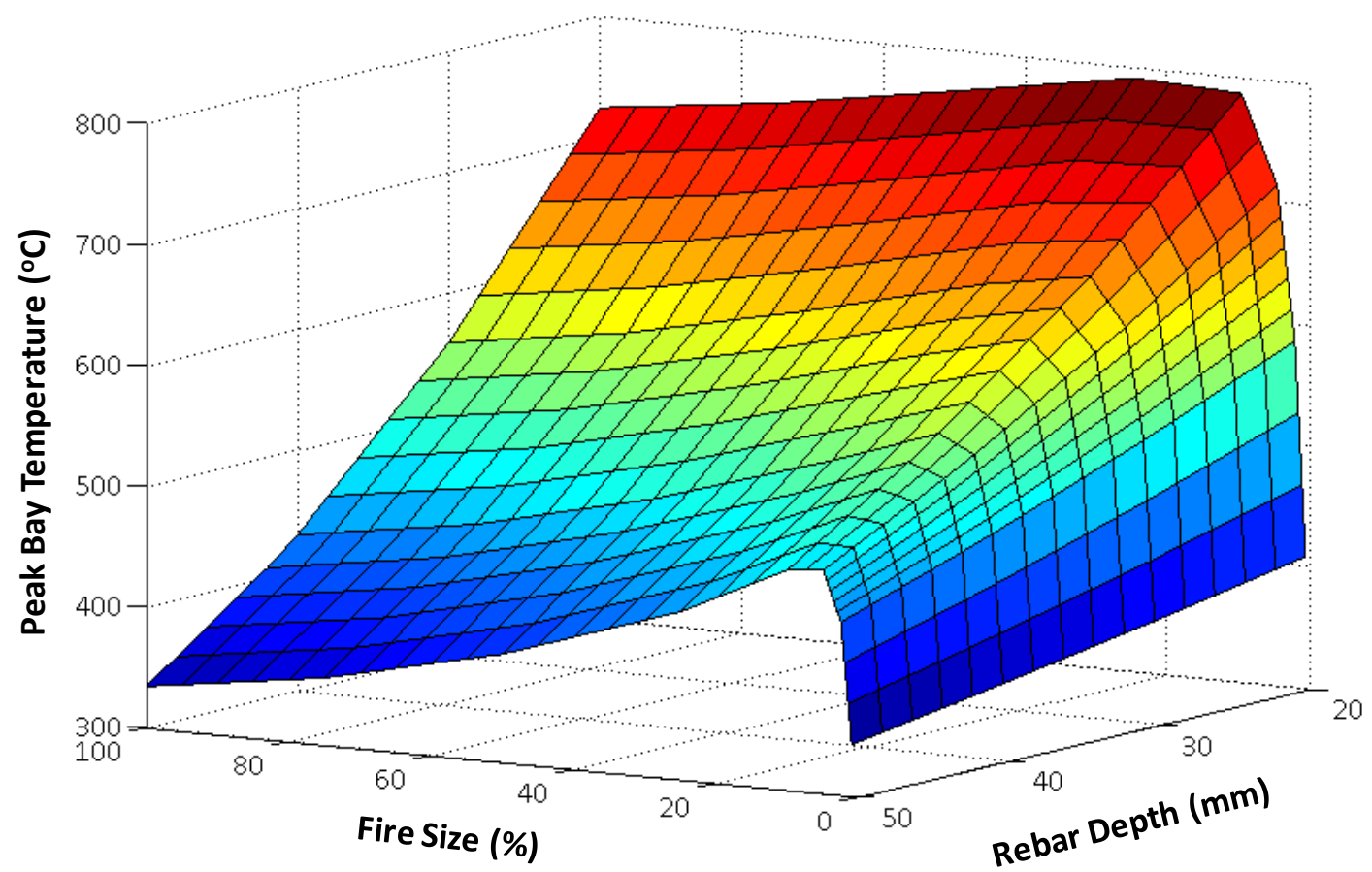

(b)

Figure 2.9: (a) Gas phase and bay temperatures for rebar depths of 20, 30, 42 and 50mm; (b) Peak bay temperature vs. fire area and rebar depth for $\Delta x=0.21 \mathrm{~m}$. 


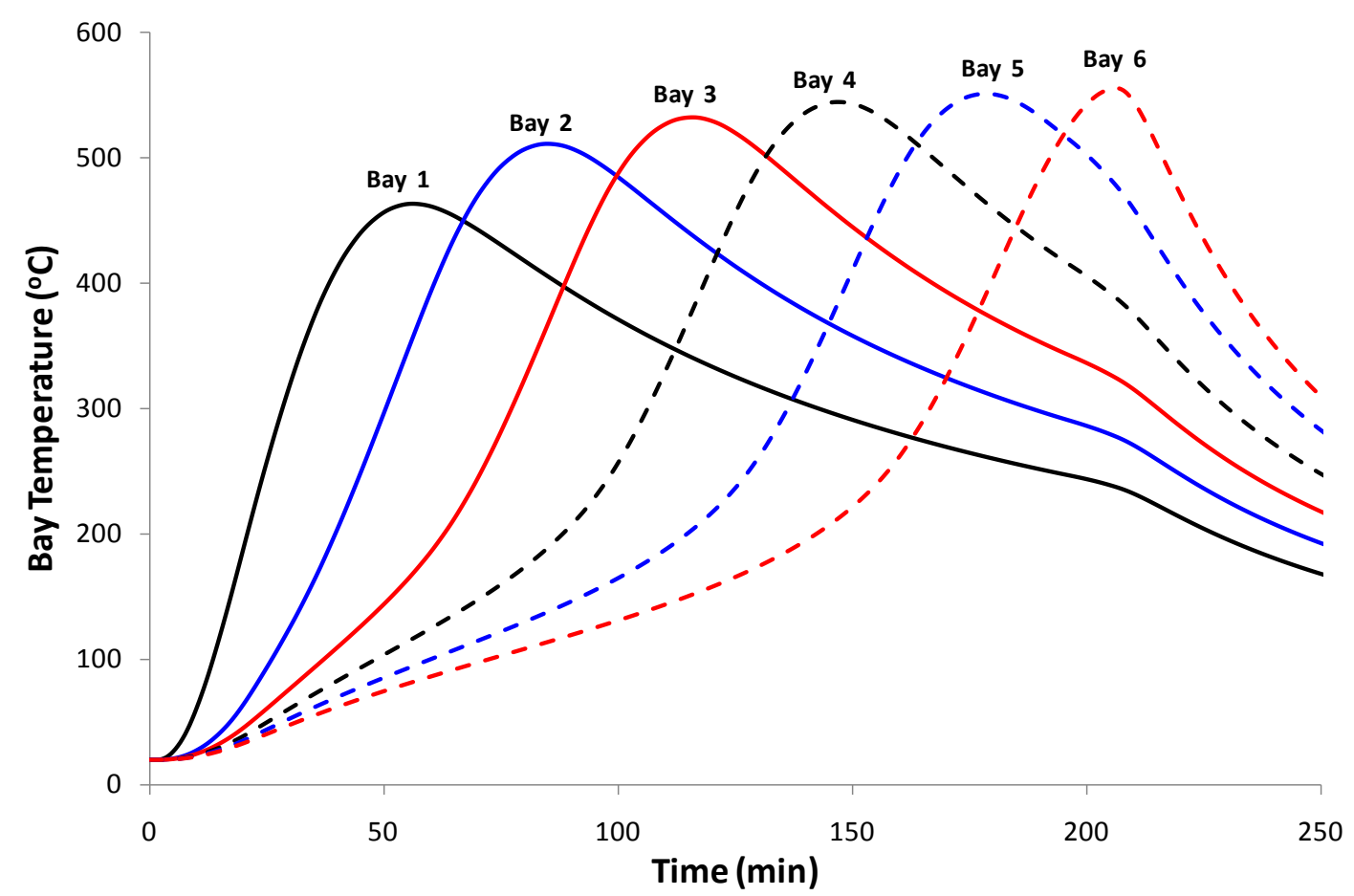

(a)

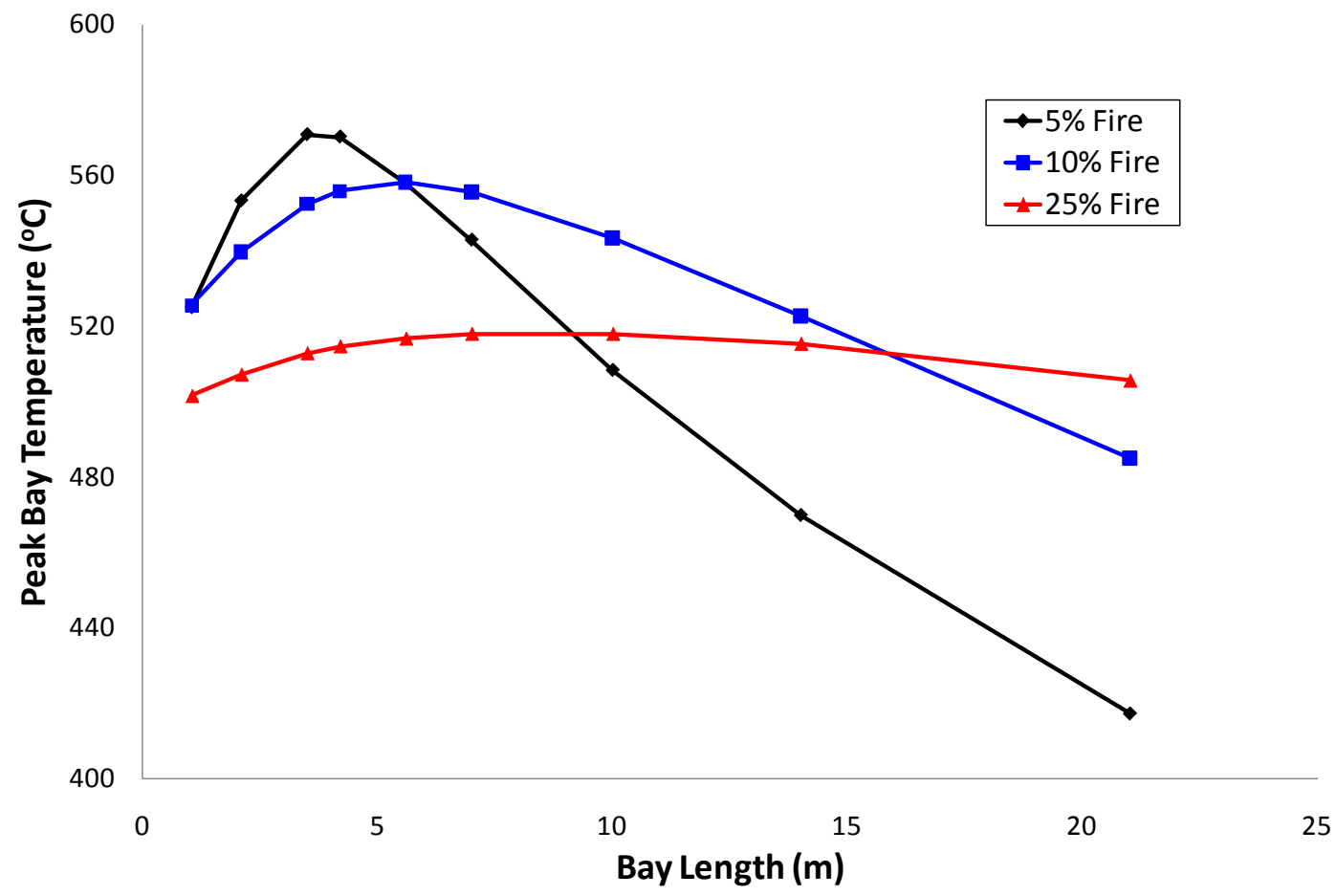

(b)

Figure 2.10: (a) Bay temperatures vs. time for each bay in the structure along its length; (b) Variation of peak bay temperature with bay length for $5 \%, 10 \%$ and $25 \%$ fire sizes. 



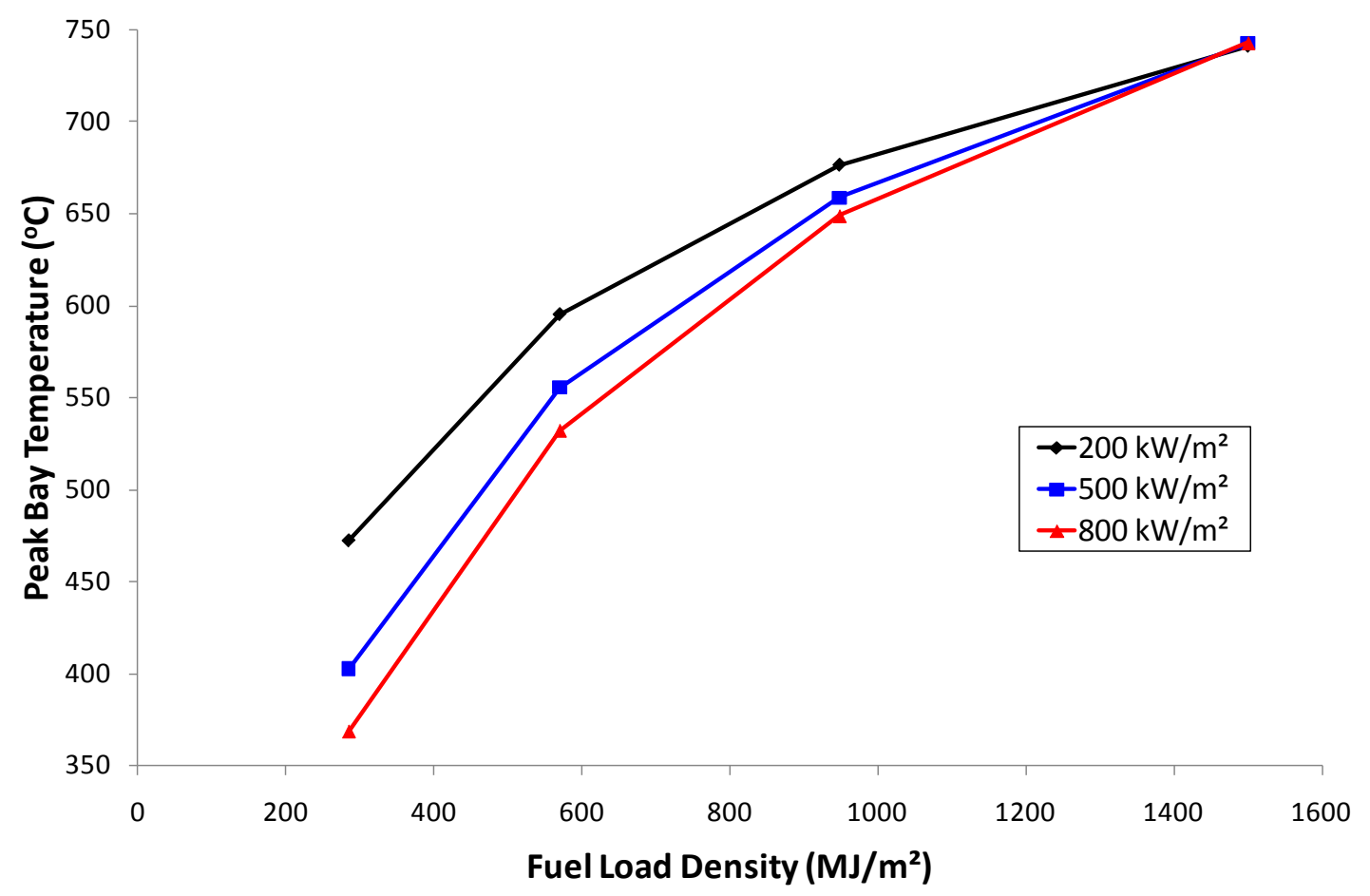

Figure 2.11: Peak bay temperature vs. fuel load density for a range of heat release rates per unit area. 


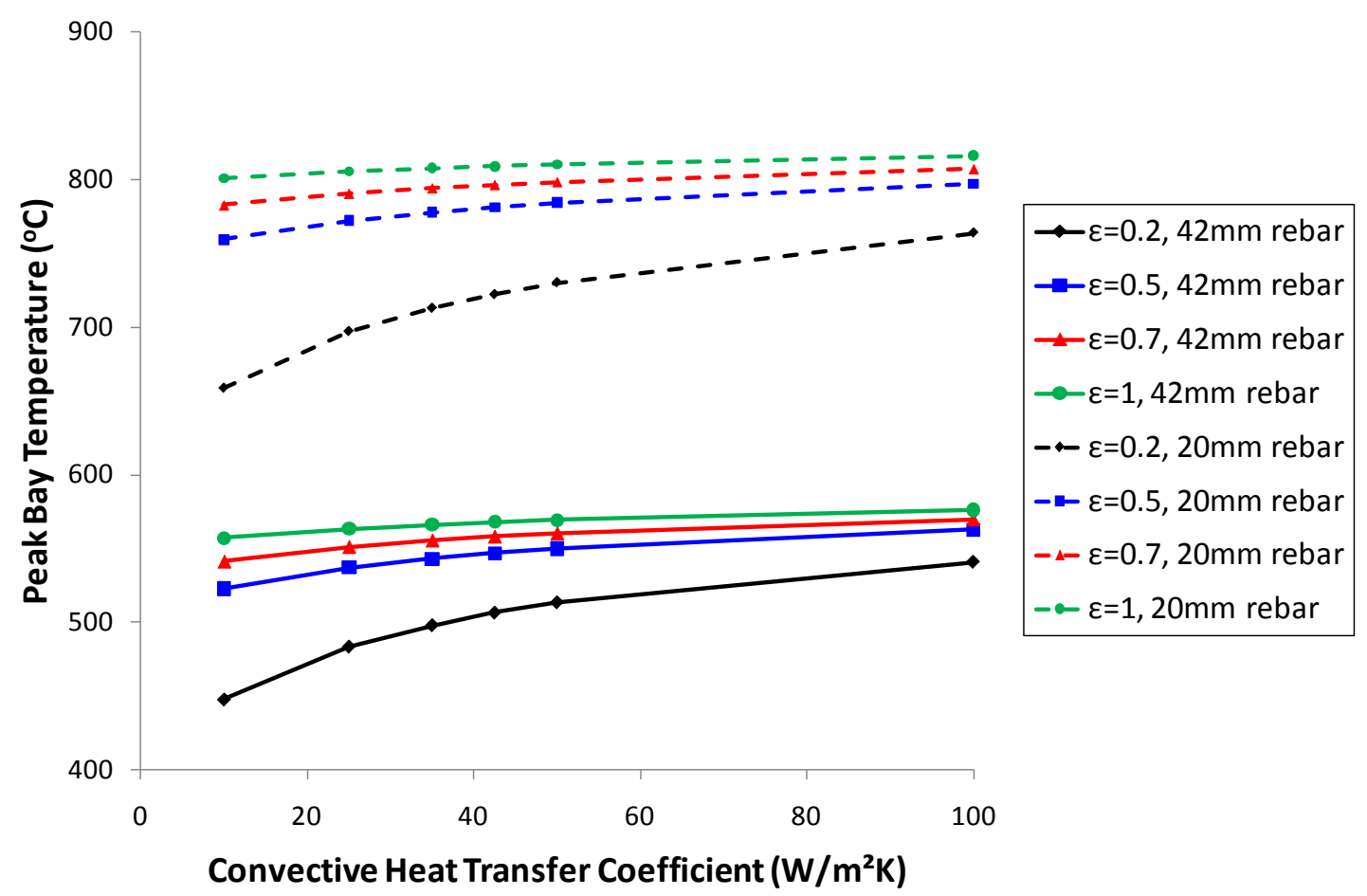

Figure 2.12: Peak bay temperature vs. convective heat transfer coefficient for a range of material emissivities and rebar depths. 


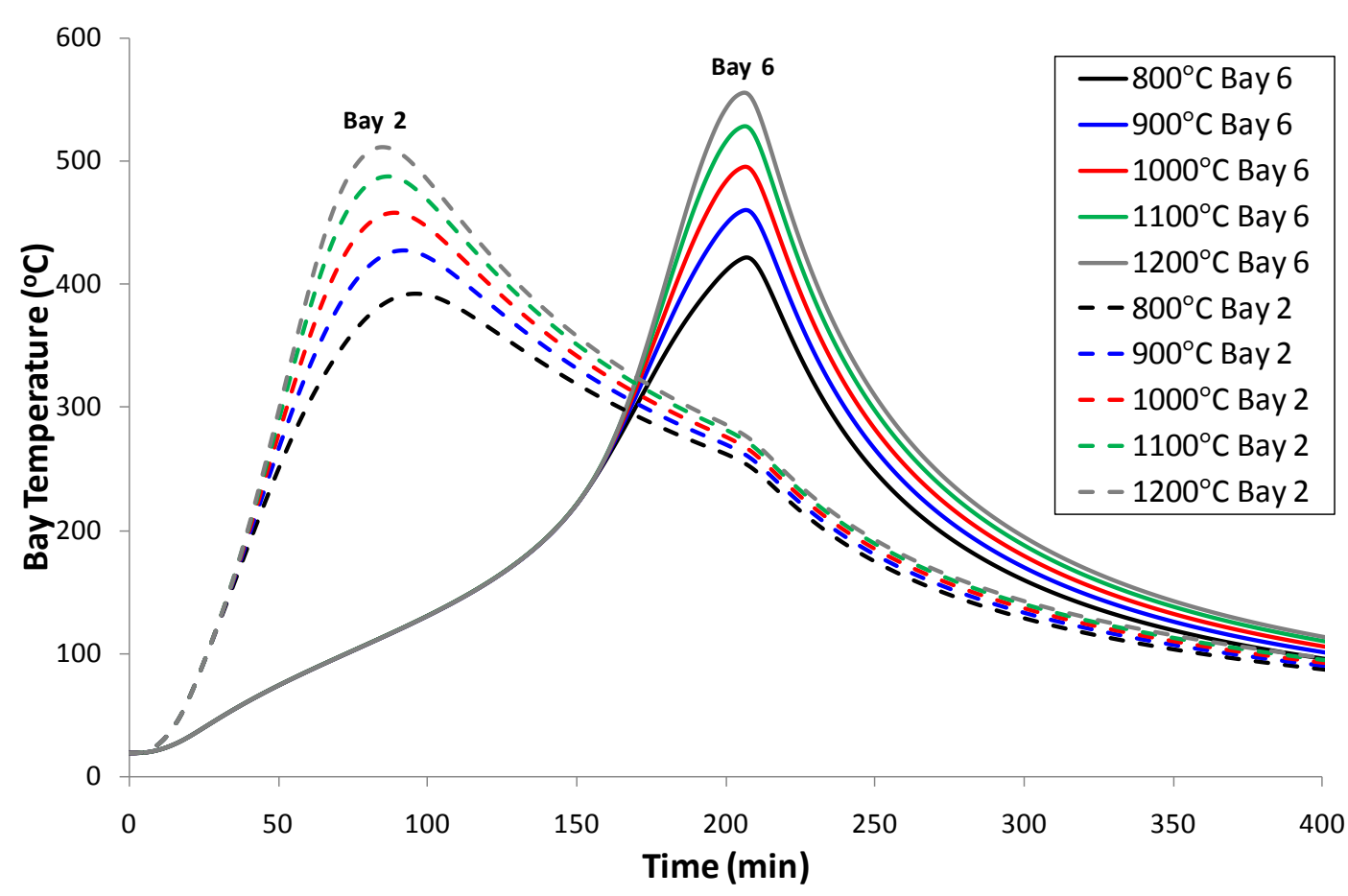

Figure 2.13: Bay temperature vs. time for near field temperatures between 800 and $1200^{\circ} \mathrm{C}$ at Bays 2 and 6. 


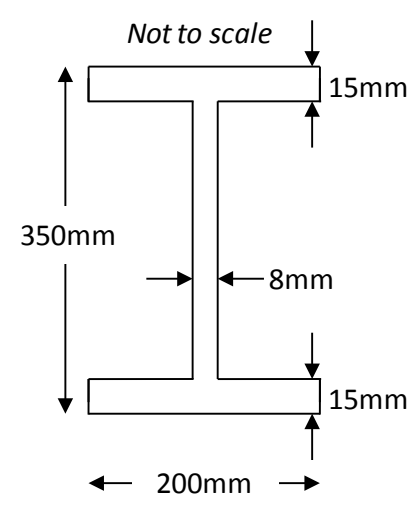

Figure 2.14: Dimensions of the steel beam section analysed. 


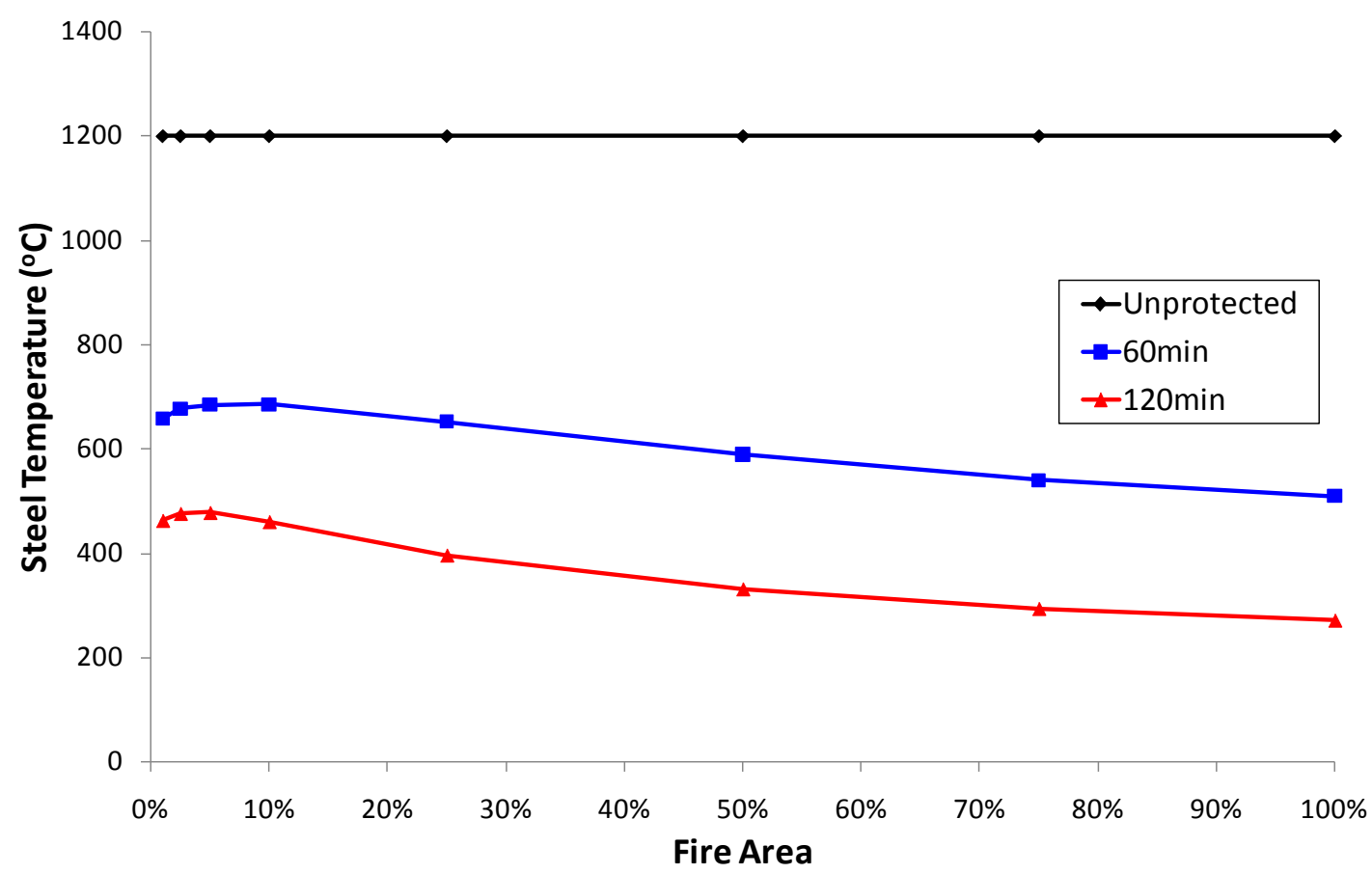

Figure 2.15: Peak steel temperature vs. fire size for unprotected, $60 \mathrm{~min}$ rated, and $120 \mathrm{~min}$ rated steel beams at the far end of Bay 6 for a grid size of $\Delta x=0.21 \mathrm{~m}$. 


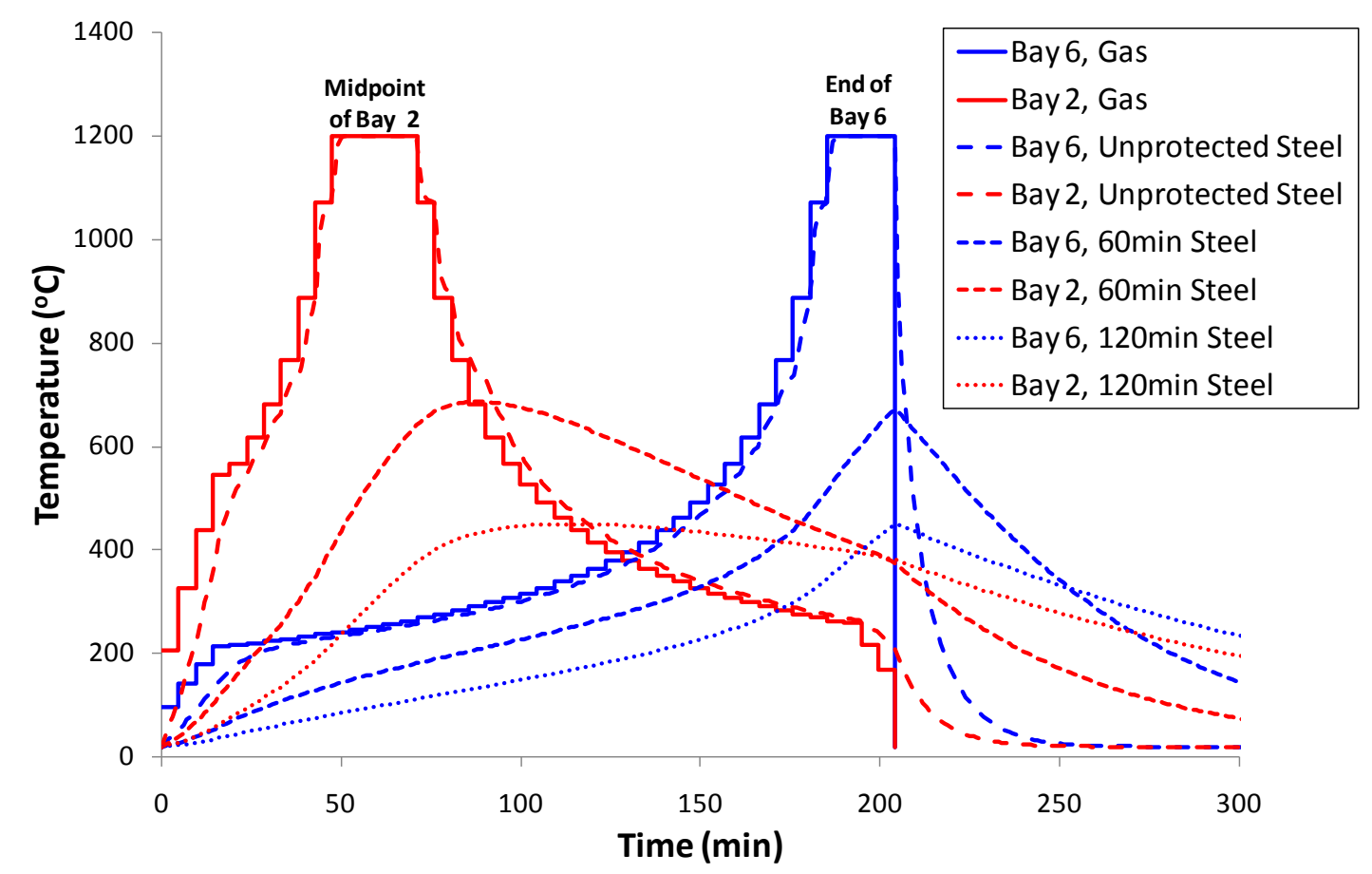

Figure 2.16: Temperature vs. time for the gas phase plus all three steel beam types at the midpoint of Bay 2 and the far end of Bay 6 . 


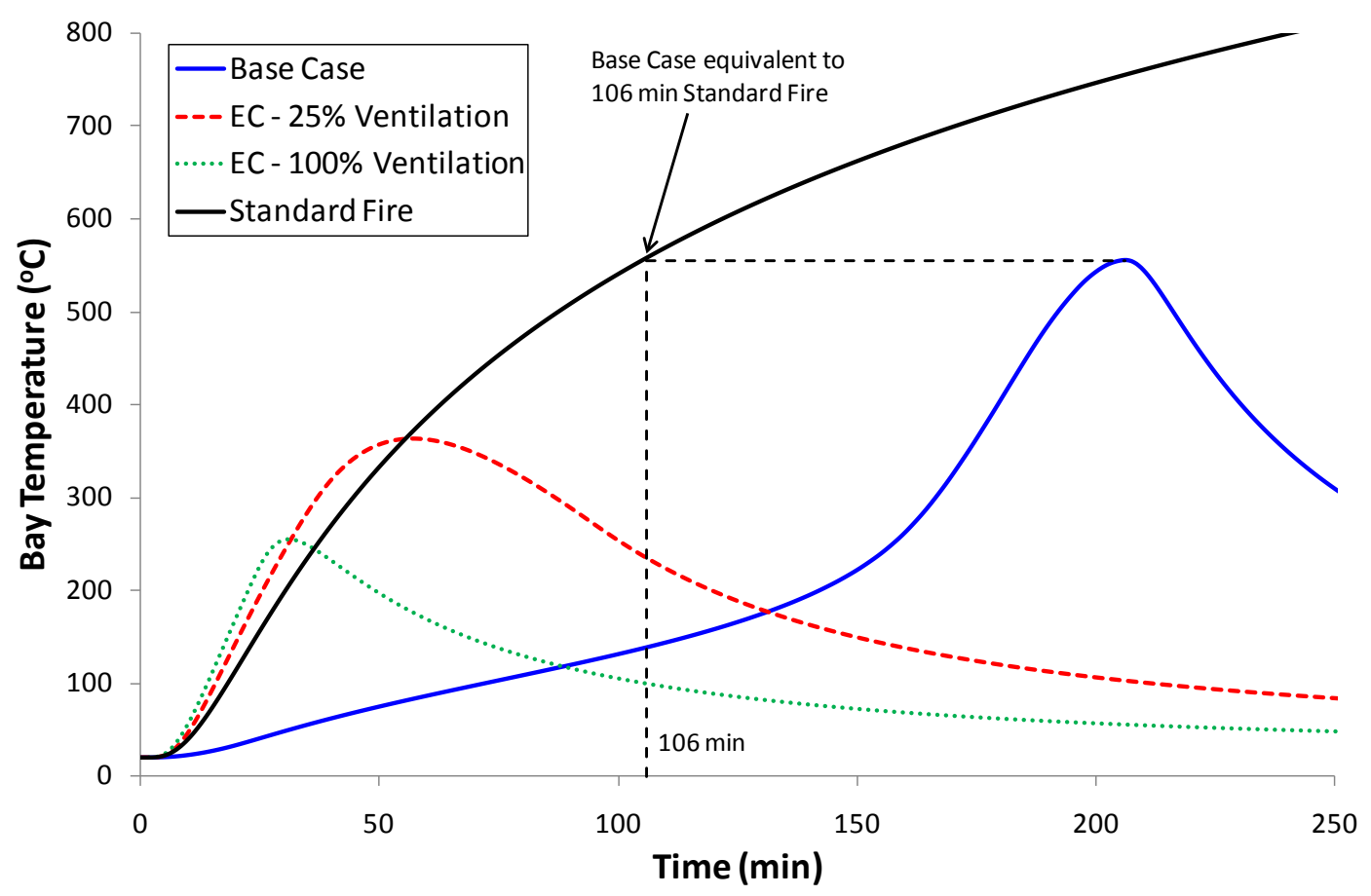

Figure 2.17: Comparison of bay temperatures calculated using the base case, the standard fire, and two Eurocode parametric temperature-time curves. 


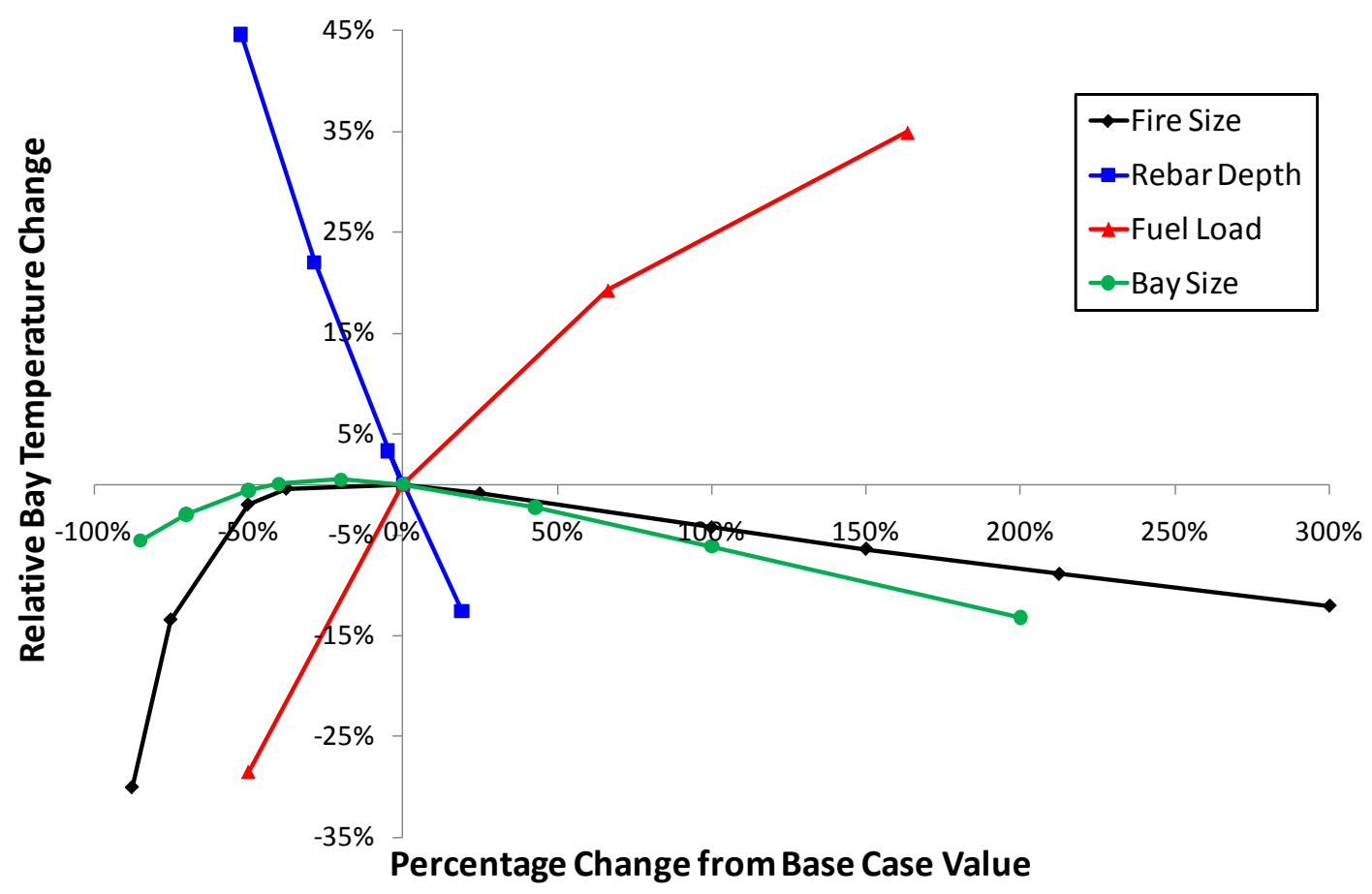

(a)

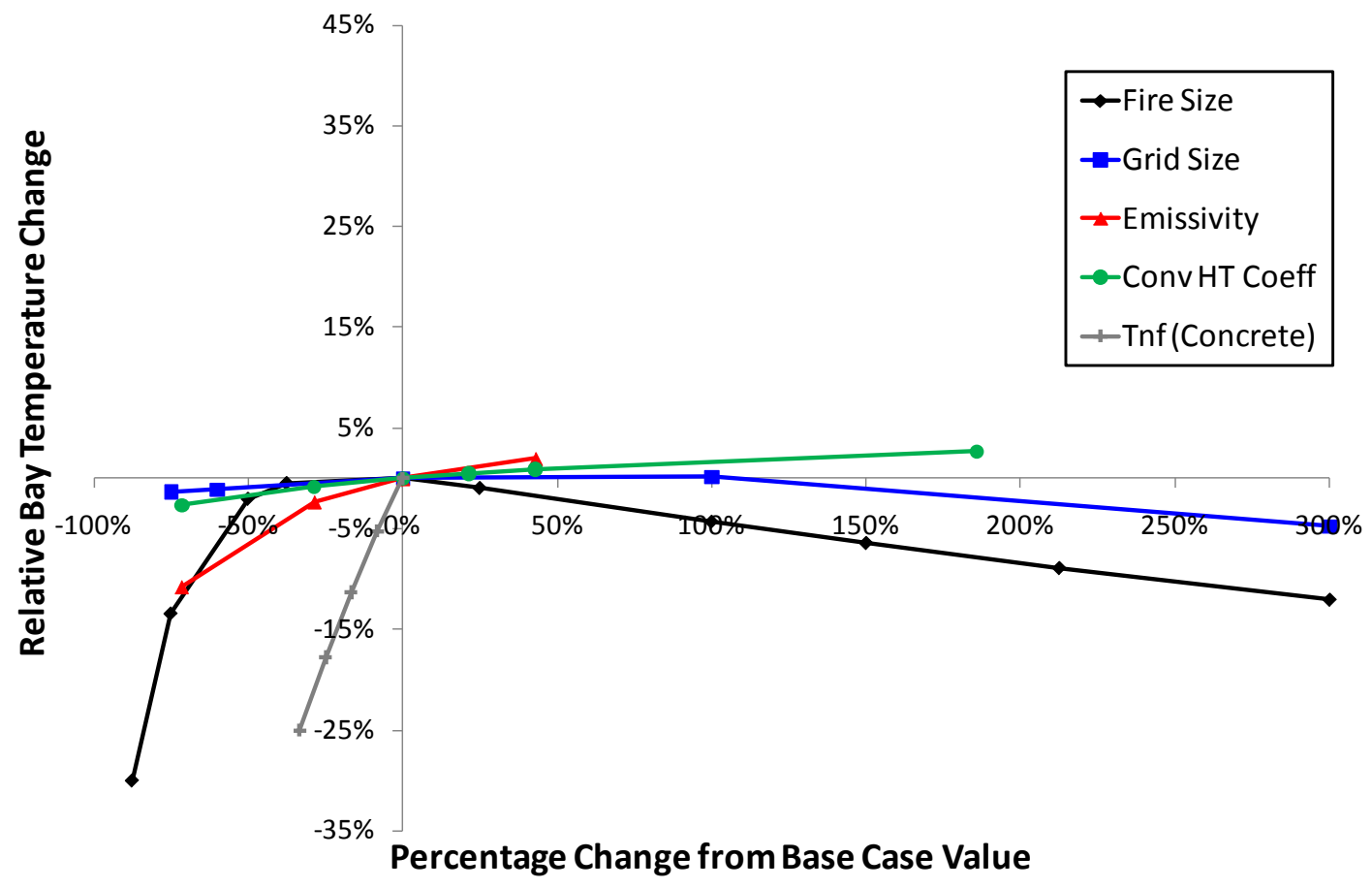

(b)

Figure 2.18: Relative change in bay temperature vs. percentage change in each (a) building parameter and; (b) physical or numerical parameter. 